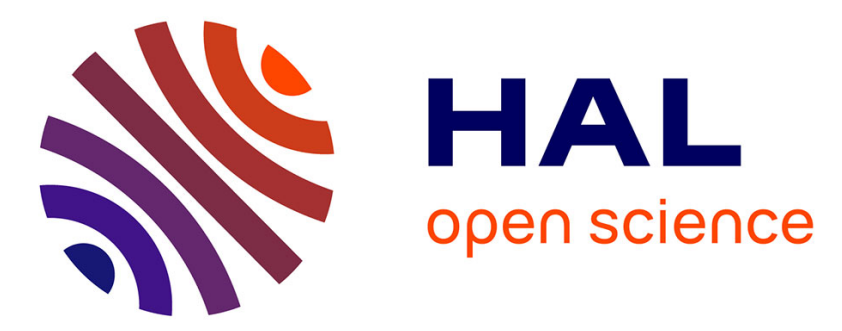

\title{
3D simulation of a power ramp including fuel thermochemistry and oxygen thermodiffusion
}

P. Konarski, J. Sercombe, C. Riglet-Martial, L. Noirot, I. Zacharie-Aubrun, K. Hanifi, M. Fregonese, P. Chantrenne

\section{- To cite this version:}

P. Konarski, J. Sercombe, C. Riglet-Martial, L. Noirot, I. Zacharie-Aubrun, et al.. 3D simulation of a power ramp including fuel thermochemistry and oxygen thermodiffusion. Journal of Nuclear Materials, 2019, 519, pp.104-120. 10.1016/j.jnucmat.2019.03.021 . hal-02405439

\section{HAL Id: hal-02405439 \\ https://hal.science/hal-02405439}

Submitted on 22 Oct 2021

HAL is a multi-disciplinary open access archive for the deposit and dissemination of scientific research documents, whether they are published or not. The documents may come from teaching and research institutions in France or abroad, or from public or private research centers.
L'archive ouverte pluridisciplinaire HAL, est destinée au dépôt et à la diffusion de documents scientifiques de niveau recherche, publiés ou non, émanant des établissements d'enseignement et de recherche français ou étrangers, des laboratoires publics ou privés.

\section{(ㄷ)(1) $\$$}

Distributed under a Creative Commons Attribution - NonCommerciall 4.0 International 


\title{
$3 \mathrm{D}$ simulation of a power ramp including fuel thermochemistry and oxygen thermodiffusion
}

\author{
P. Konarski ${ }^{1,2}$, J. Sercombe ${ }^{1}$, C. Riglet-Martial ${ }^{1}$, L. Noirot ${ }^{1}$, I. Zacharie-Aubrun ${ }^{1}$, \\ K. Hanifi ${ }^{1}$, M. Frégonèse ${ }^{2}$, P. Chantrenne ${ }^{2}$ \\ ${ }^{1}$ CEA, DEN, DEC, F-13108 Saint-Paul-lez-Durance, France. \\ 2 INSA-Lyon, MATEIS UMR 5511, F-69621 Villeurbanne, France. \\ e-mail: piotr.konarski@cea.fr, jerome.sercombe@cea.fr
}

\begin{abstract}
This paper presents 3D simulations of power ramps in pressurized water reactors with the fuel performance code ALCYONE, which is part of the computing environment PLEIADES. The code has been upgraded to couple the description of irradiated fuel thermochemistry already available with oxygen transport taking into account thermodiffusion. The impact of oxygen redistribution during a power transient on irradiated fuel thermochemistry in the fuel and on chemically reactive gas release from the fuel $\left(\mathrm{I}_{(g)}, \mathrm{I}_{2(g)}, \mathrm{CsI}_{(g)}, \mathrm{TeI}_{2(g)}, \mathrm{Cs}_{(g)}, \mathrm{Cs}_{2(g)}\right)$ is studied. The simulations show that oxygen redistribution, even if moderate in magnitude, leads to the reduction of metallic oxides (molybdenum dioxide, cesium molybdates, chromium oxide) at the fuel pellet center and consequently to the release of a much greater quantity of gaseous cesium. Pellet-Cladding Interaction failure propensity is shown to decrease in consequence of the thermodynamically favourable reaction of iodine with released cesium in the free volume of the rod.
\end{abstract}

\section{Keywords}

nuclear fuel, thermochemical modelling, oxygen potential, oxygen thermodiffusion, PCI, I-SCC, iodine partial pressure, numerical simulation 


\section{Introduction}

During irradiation, the composition and the structure of the fuel vary in both space and time. Numerous Fission Products (FPs) and actinides create together a very complex chemical system. This system is separated from the coolant by the cladding. The integrity of the cladding ensures the confinement of the FPs in the fuel rod. In Pressurized Water Reactors (PWRs), Pellet-Cladding Interaction (PCI) induced by fuel cracking, swelling and the non uniform axial pellet deformation combined with the release of iodine from the fuel pellet center may lead to PCI failure of the cladding by Iodine Stress Corrosion Cracking (I-SCC) [1,2] in transient conditions (class 2 power ramp).

In recent years, progress has been made in the development of fuel performance codes where the FP inventory and the thermochemical state of FPs in the fuel pellet can be assessed during normal [3], off-normal (power ramps) irradiation or accidental conditions, some of which coupled to sophisticated Fission Gas Release (FGR) models [4-6]. In PCI failure analyses, the coupling of thermochemistry and thermo-mechanics allows one to investigate both chemical and mechanical factors simultaneously [6]. It is particularly interesting for the understanding of the behavior of doped fuels that have shown an improved resistance to PCI failure [7].

In a recent paper on power ramped Cr-doped fuels [8], it was shown that the oxygen potential along the fuel radius decreases significantly during the high power period of a power ramp. These results were attributed to oxygen thermodiffusion (diffusion of oxygen from the hot pellet center to the cold pellet periphery), a phenomenon observed not only in Sodium Fast Reactor (SFR) fuels due to the high temperature gradients at hand in these fuels $[9,10]$, but also in BWR power ramped fuel pellets as reported by Adamson et al. [11]. Similar observations were reported on Gd-doped fuel pellets after a power ramp [12]. Electron Probe Micro-Analysis (EPMA) measurements showed lower oxygen concentration in the central part of the Gd-doped fuel pellet after irradiation in comparison to fresh fuel. The change in oxygen potential during a power transient affects the chemical speciation of the FPs and it would therefore be interesting to consider it in PCI simulations.

Several papers dealing with oxygen transport in hyperstoichiometric fuel pellets have been proposed in the last two decades, usually concerned with the treatment in 2D or 3D of the original 1D oxygen transport models available for nuclear fuels [13]. Most of the papers aimed at studying the impact of oxygen transport (including thermodiffusion) on the thermal and mechanical properties of the fuel, and, hence, at quantifying the related increase of fuel pellet temperatures during typical in-reactor power sequences [14-16]. Oxygen transport was also considered in simulations of defective fuels to model the increase in fuel stoichiometry in consequence of fuel oxidation by vapor water, resulting in a pronounced degradation of the fuel thermal properties and possibly to fuel melting [17] [18]. The authors implemented coupled thermal and oxygen transport models based on fuel properties established on non irradiated materials. The impact of oxygen transport on the thermochemical state of FPs and dopants in nuclear fuels has received less attention, partly because of the difficulties encountered in the coupling of oxygen transport and irradiated fuel thermochemistry [19]. Recently, Simunovic et al. proposed a formulation of oxygen 
and heat transport that can be used with irradiated fuel thermochemistry, in which the driving force for mass transport is the Planck potential of oxygen [20].

In this paper, 3D thermochemical-mechanical simulations of PWR power ramps on Cr-doped $\mathrm{UO}_{2}$ with the fuel performance code ALCYONE including oxygen transport are presented. The main purpose of the latter development is to study the impact of oxygen redistribution on irradiated fuel thermochemistry and on chemically reactive fission gas release. A new method is proposed in this work to couple oxygen transport and irradiated fuel thermochemistry. It ensures fast calculations, which make 3D simulations possible and guarantees the simultaneous conservation of oxygen atoms and vacancies in the pellet. Section 2 presents the fuel performance code ALCYONE and the main models used in the coupled simulation. Section 3 details the modelling of oxygen transport. Simulation results are shown and discussed in section 4 .

\section{The fuel performance code ALCYONE}

ALCYONE is a multidimensional fuel performance code, part of the PLEIADES computational environment co-funded by CEA, EDF and FRAMATOME [21]. ALCYONE is able to perform simulations of the fuel rod behavior in normal conditions, power ramps and accidental conditions [22]. PCI is described precisely in ALCYONE by the 3D simulation of a fuel pellet fragment with the overlying cladding. A typical Finite Element (FE) mesh used in the simulations is shown in Figure 1.

The fuel performance code ALCYONE includes a number of modules that can be used independently or called at each node of the mesh [22]. A typical coupled calculation requires the following successive steps, which are run iteratively until convergence of the four main fields (temperature, displacements, stresses and fission gas-induced swelling strains) is achieved:

- a neutronics calculation to estimate the power deposition at each node of the FE mesh,

- a thermo-mechanical calculation of the fuel-gap-clad system to estimate the temperature, displacements and stresses at each node of the FE mesh,

- a fission gas calculation, which concerns only the bulk of fission gases in the fuel pellet, i.e., the fission products or noble gases Xe and $\mathrm{Kr}$ (chemically inert), and gives estimates of FGR and fission gas swelling at each node of the FE mesh,

- a thermochemical calculation to estimate the chemical speciation of FPs other than noble gases and their release at each node of the mesh. The term Chemically reactive Fission Gas Release (CFGR) will be used to refer to the release of gas species other than noble gases, which are chemically reactive.

Since the current calculation scheme of ALCYONE includes several physical phenomena, it is often referred to as a multi-physics computation. The main steps and associated models are detailed in the next section. 


\section{$2.1 \quad$ Neutronics}

The first step in modelling nuclear fuel is to compute the power deposition. In ALCYONE, this is done with PRODHEL, a CEA neutronics model that can be used as a stand-alone program or within the PLEIADES computational environment [23]. Initially, only the chains of actinoids ( $\mathrm{U}, \mathrm{Pu}, \mathrm{Am}, \mathrm{Cm}, \mathrm{Np}$ ) were taken into account in PRODHEL in order to compute the radial power density profile in the fuel pellet and the local helium production due to $\alpha$ decay. Recently, PRODHEL has been extended to the following fission products: Xe, Kr, Cs, Rb, I, Br, Te, Se, Mo, Tc, Ru, Rh, Pd, Sr, Ba, Y, La, Nd, Pm, Eu, Gd, Ce, Pr, Nb and Zr. The model uses the neutronics database JEFF 3.1.1 of JANIS [24]. Overall, PRODHEL includes 199 isotopes of FPs and 23 isotopes of actinides. Only isotopes having a significant impact on the isotopic inventory are considered, i.e., isotopes with neutronics cross-sections above 0.1 barn. PRODHEL has been successfully validated by comparison to $\mathrm{UO}_{2}$, MOX and Gd-doped fuel irradiation simulations performed with the evolution code CESAR [25] used previously to estimate the FPs inventory [6] or with the core neutronics code APOLLO [26], the reference at CEA for neutronics calculations. PRODHEL is thus a versatile model of PLEIADES that can be easily adapted to meet users' requirements.

\subsection{Thermomechanics}

The thermo-mechanical calculation is rather standard for fuel performance codes and has been already detailed by Michel et al. [27] and Sercombe et al. [28]. In brief, ALCYONE relies on the FE code Cast3M [29] for the thermo-mechanical calculations. They account for many non-linearities, either related to material behavior (e.g., fuel and clad creep, clad plasticity, fuel cracking) or structural behavior (e.g., pellet-clad unilateral contact with friction, axial locking of the pellet and the cladding). The 3D scheme was developed specifically for PCI analyses since it allows a precise description of stress-strain localization at the so-called triple point [27] (in front of a pellet radial crack and pellet end, at the clad inner wall) where PCI failures in PWRs typically occur during class 2 power transients [30].

\subsection{Fission gas behavior}

MARGARET is a mechanistic model dealing with the bulk of fission gases (i.e., the FPs or noble gases $\mathrm{Xe}$ and $\mathrm{Kr}$, which are chemically inert) [31]. It describes the transport of noble gases within the fuel microstructure in various conditions including nominal irradiation, power transients or accidental conditions. MARGARET is called by ALCYONE at each time step and each node to estimate the Fission Gas Release and fission gas induced swelling. It is a local model describing gas behavior at the grain scale. A distinction between intra- and inter-granular gas populations is made. At high temperatures occurring during off-normal conditions (class 2 power ramp), the noble gases created within the grain form intra-granular bubbles that migrate towards the grain face due to the thermal gradient. The gas reaching the grain face forms inter-granular bubbles. Eventually, the growing inter-granular bubbles connect on the grain surface to form channels. These channels can eventually 
form a continuous porous network at the grain boundaries that is connected to the open porosity. FGR occurs when the pressure in these channels is greater than the plenum pressure.

\subsection{Irradiated fuel thermochemistry}

All thermodynamic calculations are carried out using the code ANGE [32] (for AdvaNced Gibbs Energy), which is based on SOLGASMIX [33]. ANGE uses the Gibbs energy minimization method to find the thermodynamic equilibrium of the multicomponent and multiphase system at a given temperature, pressure and composition. The calculations require an extensive thermodynamic database including all possible chemical compounds, both in gaseous phase and condensed phase (solid solution in the fuel matrix or separate stoichiometric solid or liquid compounds). For the sake of simplification, the elements (actinides and FPs) having similar chemical behavior are grouped according to 14 chemical families with one representative element for each of them, as summarized in Tab. 1. The different phases (solid solution phase, gas phase, stoichiometric separate phases and noble metals phase) and species considered in the ANGE database are briefly discussed below:

- The fluorite oxide solid solution phase includes binary and ternary compounds of U, Pu, rare earth, Eu, $\mathrm{Zr}$ and $\mathrm{Cr}$. The description of the hypo- and hyperstoichiometric domains of the U-Pu-O system is based on the work of Lindemer and Besmann [34] [35]. The thermodynamic representation of rare earths solubility is detailed in Lindemer and Brynestad [36]. The data and solubility model for Eu and $\mathrm{Zr}$ have been proposed by Dumas [37]. The U-Cr-O model is based on the work of Riglet-Martial [38]. Overall, the solid solution phase contains 17 species that will be noted with the ${ }_{s s}$ subscript in the paper.

- The gas phase is composed of 61 species. It includes gases important for PCI such as $\mathrm{Cs}_{(g)}, \mathrm{Cs}_{2(g)}, \mathrm{CsI}_{(g)}, \mathrm{I}_{(g)}, \mathrm{I}_{2(g)}, \mathrm{TeI}_{2(g)}$ and $\mathrm{Cs}_{2} \mathrm{MoO}_{4(g)}$.

- The stoichiometric separate phases include solid and liquid uranates, molybdates and zirconates, such as $\mathrm{Cs}_{2} \mathrm{UO}_{4(s)}, \mathrm{Cs}_{2} \mathrm{MoO}_{4(s, l)}, \mathrm{Cs}_{2} \mathrm{ZrO}_{3(s)}, \mathrm{BaZrO}_{3(s)}$, and other important compounds such as $\mathrm{MoO}_{2(s)}, \mathrm{MoO}_{3(s, l)}, \mathrm{CsI}_{(s, l)}, \mathrm{Te}_{(s, l)}$, $\mathrm{Cs}_{(s, l)}, \mathrm{Cs}_{2} \mathrm{Te}_{4(s, l)}, \mathrm{BaTe}_{(s)}$. A total of 80 stoichiometric separate phases is considered in the database.

- The noble metals phase includes 3 representative species that are often observed simultaneously in irradiated fuels in amalgam form: $\mathrm{Mo}_{(s)}, \mathrm{Ru}_{(s)}$ and $\operatorname{Pd}_{(s)}$.

The outputs of ANGE include the concentration of all the chemical species that are likely to appear, the ratio of oxygen to metal atoms in the fluorite solid solution phase $\left(\mathrm{O} / \mathrm{M}\right.$ with $\left.\mathrm{M}=\mathrm{U}+\mathrm{FP}_{s s}\right)$ and the "oxygen potential of the fuel" $\Delta G_{\mathrm{O}_{2}}=R T \ln \left(p_{\mathrm{O}_{2}}\right)$ with $R$ the gas constant $[\mathrm{J} / \mathrm{mol} / \mathrm{K}], T$ the temperature $[\mathrm{K}]$ and $p_{O_{2}}$ the oxygen partial pressure [bar]. $\Delta G_{\mathrm{O}_{2}}$ is equal to the difference between the chemical potential of oxygen in the solid and that of pure gaseous oxygen at the same temperature and at 1 bar pressure [39] [40]. 


\section{$3 \quad$ Modelling oxygen transport}

\subsection{Transport equation with thermodiffusion}

In SFRs, oxygen, uranium and plutonium radial migration in the fuel have been observed and quantified [41] and are associated to thermodiffusion. In PWRs, one may restrict the analysis to oxygen, the most mobile element, since fuel temperatures are usually not exceeding $1000{ }^{\circ} \mathrm{C}$ during base irradiation (long-term) and $2000{ }^{\circ} \mathrm{C}$ during power ramps (short-term). According to the underlying theory, oxygen transport with thermodiffusion describes the movement of oxygen point defects (interstitials or vacancies) under simultaneous temperature and concentration gradients. The equations describing solid-state thermodiffusion of oxygen in uranium oxides were formulated to explain the radial oxygen redistribution in initially nonstoichiometric but homogeneous $\mathrm{UO}_{2 \pm x}$ samples [9]. A good review of the theory and equations has been provided by Welland [10]. In the case of the transport of a dilute concentration of oxygen vacancies in hypo-stoichiometric fuels, which are considered in this work for a reason that will be explained in the next section, the vacancy flux reads as follows:

$$
J_{v}=-n D\left(\nabla c_{v}+\frac{c_{v} Q^{*}}{F_{T D} R T^{2}} \nabla T\right)
$$

where $c_{v}$ is the atomic fraction of vacancies on the oxygen anion sites $[\mathrm{mol} / \mathrm{mol} \mathrm{O}]$, $n$, the concentration of oxygen atoms in the fuel $\left[\mathrm{mol} \mathrm{O} / \mathrm{m}^{3}\right], T$ the temperature $[\mathrm{K}]$, $D$ the oxygen chemical diffusion coefficient $\left[\mathrm{m}^{2} / \mathrm{s}\right], Q^{*}$ the heat of transport of oxygen vacancies $[\mathrm{J} / \mathrm{mol}], R$ the gas constant $[\mathrm{J} / \mathrm{mol} / \mathrm{K}]$ and $F_{T D}=\partial \ln \mu_{v} / \partial \ln c_{v}$ the thermodynamic factor [unitless] with $\mu_{v}$ the chemical potential of oxygen vacancies $[\mathrm{J} / \mathrm{mol}]$. The vacancy transport mechanism is considered because the thermochemical calculations performed in this work show that an initially stoichiometric fuel becomes slightly hypo-stoichiometric with irradiation (see next section). In nonirradiated fuels, it has been shown experimentally that if the material is initially hypo-stoichiometric, oxygen migrates from the hot part to the cold part of the pellet [9], implying that the heat of transport is negative $\left(Q^{*}<0\right)$.

Applying the equation of continuity, the transient state might be described by the following equation [13]:

$$
\frac{\partial c_{v}}{\partial t}=\nabla \cdot\left[D\left(\nabla c_{v}+\frac{c_{v} Q^{*}}{F_{T D} R T^{2}} \nabla T\right)\right]
$$

In non-irradiated $\mathrm{UO}_{2 \pm x}$ fuels, instead of using the concentration of oxygen vacancies, $c_{v}$, one may use alternatively the stoichiometry deviation, $x$ [unitless], or the oxygen over metal ratio, $O / M$ [unitless] (with $M=U+P u$ ). The relation between them is as follows:

$$
2 c_{v}=x=2-O / M
$$

\subsection{Application to irradiated fuel}

The U-O system, representative of unirradiated uranium dioxide fuel, has been carefully examined over the years and its thermodynamic behavior is well characterized. 
The thermochemical parameters temperature and partial oxygen pressure are known to affect the stoichiometry deviation, expressed as $x$ in $\mathrm{UO}_{2 \pm x}$. As shown in Figure 2 , the evolution of the partial oxygen pressure in unirradiated $\mathrm{UO}_{2 \pm x}$ fuel with the temperature and the $\mathrm{O} / \mathrm{M}$ ratio is satisfactorily reproduced with the ANGE code. The thermodynamic model proposed by Lindemer and Besmann [34] works well when compared to the set of data gathered by Guéneau et al. [42].

Defining the stoichiometry deviation of irradiated fuel is more problematic. Incorporation of FPs with various valencies into the initial $\mathrm{UO}_{2}$ matrix changes the $\mathrm{O} / \mathrm{M}$ ratio (defined as $\mathrm{O} /\left[\mathrm{U}+\mathrm{FP}_{(s s)}\right]$ ) of the material. For instance, trivalent rare earths, highly abundant FPs in irradiated fuel, can be incorporated in the lattice. Figure 3, adapted from Olander [39], illustrates the consequences of FP incorporation in the uranium dioxide solid solution.

The left sketch shows the state before irradiation, the system contains only oxygen anions and uranium cations. The right sketch shows the system with 2 trivalent FPs cations that replaced 2 uranium cations after fission. Electrical neutrality implies the creation of an anion vacancy in the fluorite structure. In consequence, the $\mathrm{O} / \mathrm{M}$ ratio of the system decreases compared to its initial value. Walker et al. [43] estimated, from Inductively Coupled Plasma Mass Spectrometry (ICP-MS) measurements and from a theoretical oxygen balance between the solid solution and oxide second phases, the radial profile of $\mathrm{O} / \mathrm{M}$ ratio in a PWR fuel pellet irradiated up to an average burnup of $100 \mathrm{GWd} / \mathrm{tU}$. Depending on the proportion of second oxide phases containing $\mathrm{Ba}, \mathrm{Mo}$ and $\mathrm{Cs}$, they concluded that the $\mathrm{O} / \mathrm{M}$ ratio was either well below that of the initially stoichiometric $\mathrm{UO}_{2}(1.967$ at the pellet center, 1.918 at the pellet periphery) or slightly below (1.982 at the pellet center, 1.955 at the pellet periphery). Piro et al. obtained $\mathrm{O} / \mathrm{M}$ ratios below 2 in their simulations of this irradiated fuel with the RMC (Royal Military College) nuclear fuel model [44] and the Thermochimica code [3].

Unfortunately, there are very few experimental data available that can be used to check the evolution of the $\mathrm{O} / \mathrm{M}$ ratio with irradiation. Most of the experimental data concern uranium dioxides with small quantities of a single FP. The validity of the updated thermodynamic database of ANGE was checked by comparing experimental and calculated values for a number of chemical systems relevant in nuclear fuels. A good consistency was achieved, within experimental errors, between modelling and experience for the most relevant chemical systems, as illustrated in Figure 4 for $\mathrm{U}-\mathrm{O}-(\mathrm{Pu}, \mathrm{La}, \mathrm{Eu}, \mathrm{Gd})$ ternary systems.

The overall validity of the solid solution model used in ANGE was checked by numerical modelling of laboratory experiments performed on simulated irradiated fuels (SIMFUEL). Une and Oguma [45] have prepared samples simulating irradiated fuel by adding oxides of $\mathrm{Zr}, \mathrm{Nd}, \mathrm{Y}$, Ce and Pr to $\mathrm{UO}_{2}$. Three samples were prepared to simulate irradiated fuels with burnups of 2, 5 and 10 at $\%$. The authors measured the oxygen potential at $1000{ }^{\circ} \mathrm{C}$ and $1300{ }^{\circ} \mathrm{C}$ by thermogravimetry. The consequences of FPs addition were clearly observed at $1300{ }^{\circ} \mathrm{C}$ leading to a significant increase of the oxygen potential in the hyperstoichiometric domain. Experimental measurements of Une and Oguma compared to ANGE calculations are shown in Figure 5 .

The comparison confirms that the solid solution model used in ANGE is able to 
reproduce the increase in oxygen potential with the burnup.

Thermochemical calculations of irradiated fuels by several authors have shown that the oxygen potential - $\mathrm{O} / \mathrm{M}$ ratio curves significantly differ from that of non irradiated fuels because of the numerous FPs in the material $[1,46]$. In Figure 6 , the oxygen potential calculated at $1500{ }^{\circ} \mathrm{C}$ with $\mathrm{ANGE}$ is plotted as a function of the $\mathrm{O} / \mathrm{M}$ ratio of the fluorite solid solution for Cr-doped fuel, unirradiated and irradiated up to different burnups $(20,40,60 \mathrm{GWd} / \mathrm{tU})$, typical of PWR irradiation sequences. One may observe that the curve for unirradiated fuel presents a strong increase of the oxygen potential in the vicinity of the exact stoichiometry. In irradiated fuel, the oxygen potential increase is not as marked and the transition seems to be shifted towards lower values of the $\mathrm{O} / \mathrm{M}$ ratio when the fuel burnup increases.

It must be emphasized that the calculated decrease of the $\mathrm{O} / \mathrm{M}$ ratio with burnup is related to the thermodynamic database considered in ANGE. It is foreseen that the incorporation of Calphad based models in ALCYONE (in progress, see [47]) to describe irradiated fuel could lead to a better appraisal of oxygen vacancies and interstitial concentrations evolution with irradiation since these quantities are explicitly included in the thermodynamic models of Guéneau et al. [42] [48]. As of today, the application of Calphad models to irradiated fuels has just started. A reasonable agreement with measured oxygen potentials in irradiated fuels was obtained by Besmann and al. [49] only when an adjusted amount of oxygen is removed from the initial system to account for the internal oxidation of the cladding. The $\mathrm{O} / \mathrm{M}$ ratio of fluorite structure was found slightly hyperstoichiometric, in contradiction with the calculations with ANGE. In fact, it must be stressed that the evolution of the $\mathrm{O} / \mathrm{M}$ ratio in irradiated fuels is still an open question at the present time.

In this work, to model thermodiffusion of oxygen in irradiated fuel, we will keep the standard definition of stoichiometry deviation (Equation 3) with respect to stoichiometric non irradiated $\mathrm{UO}_{2}$. Equation 2 will be used to assess the redistribution of oxygen vacancies in the fuel during power transients, assuming that the incorporation of FPs upon irradiation leads to a moderate increase of oxygen vacancies in the material, as explained and corroborated by the few experimental data available in the open literature.

\subsection{Oxygen transport parameters for irradiated fuel}

Deriving the parameters for oxygen transport in irradiated fuel is another challenge. Concerning the heat of transport, most of the simulations presented in the past two decades were concerned with hyper-stoichiometric fuel and used the experimental heat of transport measured by Sari and Schumacher [9]. The thermodynamic factor was based on the Lindemer and Besmann expression of the oxygen potential [34]. None of the models were applied to hypo-stoichiometric $\mathrm{UO}_{2}$ fuels since the data of Sari and Schumacher in this domain refer to mixed oxide fuels. It must furthermore be mentioned that Sari and Schumacher's heats of oxygen transport were possibly overestimated due to thermoelectric interference with the external cover [50].

In this work, to by-pass these difficulties, we have identified the heat of transport and thermodynamic factor by inverse analysis using the weight fractions of chromium measured by EPMA along the pellet radius after several power ramps [8]. Figure 7 
illustrate the measured evolution of chromium content at the center of a fuel pellet during the $12 \mathrm{~h}$ long holding period of a power ramp (maximum power $470 \mathrm{~W} / \mathrm{cm}$ ).

Initially around $0.14 \%$, the measured $\mathrm{Cr}$ content decreases to less than $0.02 \%$ at the pellet center. Chromium solubility in the fluorite oxide matrix is known to be a function of temperature and oxygen potential, [38]. Hence, from the temperatures calculated by ALCYONE at the pellet center and the measured residual Cr content, it is possible to estimate the local oxygen potential reached during the power ramps. Thermodynamic equilibrium calculations with ANGE with prescribed oxygen potential corresponding to the measured $\mathrm{Cr}$ solubilities then give the $\mathrm{O} / \mathrm{M}$ shift at the pellet center during the $12 \mathrm{~h}$ long holding period. Assuming that steady-state oxygen thermodiffusion is reached during the $12 \mathrm{~h}$ long plateaus, the $\mathrm{O} / \mathrm{M}$ variation at the pellet center depends only on the $Q^{*} / F_{T D}$ function used in the oxygen transport equation. The heat of transport of oxygen derived from this inverse analysis is given by the following expression:

$$
Q^{*} / F_{T D}=-2.04 \times 10^{-4} \exp \left[5.35\left(4+\frac{2(O / M-2)}{0.0127 \tau_{c}}\right)\right][\mathrm{J} / \mathrm{mol}]
$$

Equation 4 is similar in its form to the one proposed by Lassmann for hypostoichiometric mixed oxide fuel [13]. Lassmann's expression was dependent on the valence of $\mathrm{Pu}\left(V_{P u}=4+\frac{2(O / M-2)}{q}\right.$ with $q$ the $\mathrm{Pu}$ mole fraction) because the deficit in oxygen was associated with plutonia assuming that the hypo-stoichiometric fuel may be considered as a solid solution of $\mathrm{UO}_{2}$ and $\mathrm{PuO}_{2-x}$. An extension of this approach to a solid solution containing several FPs leading to a hypo-stoichiometric irradiated fuel has been proposed by Baurens [51]. It basically consists in relating the heat of transport to the mole fraction of fissioned uranium atoms $\left(0.0127 \tau_{c}\right.$ with $\tau_{c}$ the burnup in at\%), the latter being an indicator of the FPs inventory in the fuel. The plot of Equation 4 shown in Figure 8 indicates a pronounced evolution of the heat of transport at a transition $\mathrm{O} / \mathrm{M}$ ratio that decreases with burnup. The corrected heat of transport estimated by Janek [50] from Sari and Schumacher's measures on uranium plutonium mixed oxide fuels is close to the function used in this work.

For the chemical diffusion coefficient of oxygen, the simple expression proposed by Lassmann [13] was adopted in the present calculations. It is given by the following expression:

$$
D=1.39 \times 10^{-6} \exp \left(\frac{-75900}{R T}\right)\left[\mathrm{m}^{2} / \mathrm{s}\right]
$$

and depends only on temperature $T$.

Models for the chemical diffusion coefficient of oxygen in unirradiated uranium oxides have been proposed recently by Berthinier et al. [52] based on an extensive review of data concerning self- and chemical diffusion coefficients and on the use of the $\mathrm{UO}_{2 \pm x}$ model of Guéneau et al. [42] to derive the thermodynamic factor. The derived chemical diffusion coefficient depends on the stoichiometry deviation and temperature. A model for oxygen diffusion in hyper-stoichiometric oxide fuel and 
hypo-stoichiometric mixed oxide fuel was also recently proposed by Moore et al. [53] [54], self-consistent with the Calphad based thermodynamic models of Guéneau et al. [42] [48]. The mobility of oxygen atoms was described in function of the concentrations in oxygen vacancies or interstitials in the $\mathrm{UO}_{2}$ or $\mathrm{PuO}_{2}$ sub-lattice and of temperature. Since the thermodynamic database of ANGE does not provide a detailed description of point defects in oxide fuels, it was not possible to include the oxygen diffusion model of Moore et al. in the calculations. It is foreseen that a better appraisal of oxygen defects distribution in irradiated fuels could stem from this approach.

\subsection{Coupling of oxygen transport and thermochemistry}

The simulations described in this paper have been performed with ALCYONE V2.0, the newest version of the code released in December 2016. Details are given in reference [22]. A schematic representation of the iterative loops included in ALCYONE V2.0 is given in Figure 9.

There are several difficulties in the combination of oxygen transport and thermochemical calculations in a fuel performance code. The main one stems from the fact that the $\mathrm{O} / \mathrm{M}$ ratio is an output of both calculations [19]. In this work, to prescribe the local $\mathrm{O} / \mathrm{M}$ ratio estimated from the oxygen transport solution in the thermochemical equilibrium calculation, a virtual element with non-zero stoichiometric coefficients for the solid solution species only is added in the solved chemical system. It leads to an additional constraint in the minimization calculation [55] that fixes the $\mathrm{O} / \mathrm{M}$ ratio. In parallel, it is considered that the total oxygen content at each node changes in proportion to the local $\mathrm{O} / \mathrm{M}$ variation since oxygen is assumed to migrate only in the solid solution. This condition ensures at each time step the simultaneous conservation of oxygen atoms and vacancies in the fuel pellet fragment.

It must be stressed that only power transients (power ramps) are simulated with the complete scheme because the high temperatures at the pellet center guarantee that thermodynamic equilibrium is reached at least in this part of the pellet. For PCI analyses, this central hot pellet center is furthermore the location where the bulk of FGR and CFGR takes place. The thermochemical - oxygen transport problem can furthermore be uncoupled to some extent during the power transient for the following reasons:

- During the short power transient (duration a few tens of seconds) that precedes the long holding period at maximum power (duration usually around 10-20 hours), oxygen migration can be neglected. For this reason, only local thermochemical equilibrium calculations are performed during the power increase phase.

- During the long holding period, power variations are usually small leading a stable temperature distribution in the fuel pellet. Since the FP content and distribution in the fuel pellet is also stable (nominal irradiation that precedes the power ramp is at the origin of the bulk of FPs), thermochemical equilibria in the pellet will evolve mainly in consequence of oxygen transport by thermodiffusion in the solid solution. Thus, during the plateau at maximum 
power, oxygen transport in the pellet is first calculated, followed by local thermochemical calculations at prescribed $\mathrm{O} / \mathrm{M}$ ratio.

- While the formation of internal zirconia during base irradiation leads to a decrease of the oxygen content in the pellet [49], there is no evidence that additional zirconia is formed during a power ramp. This result can be attributed to the slow evolution of zirconia thickness once the layer is formed [56]. In consequence, the flux of oxygen on the surface of the simulated fuel fragment during the power ramp can be assumed null at all time, meaning that the average oxygen content in the fuel pellet is constant.

This uncoupled analysis would not be possible in case of nominal irradiation since an oxygen source term that stems from the oxygen liberated by uranium fission would have to be included in the oxygen transport equation [5]. The release of oxide fission gases from the fuel pellet during the power ramp is neglected, which might prove to be wrong in the case of initially hyper-stoichiometric fuels where the excess oxygen can lead to a pronounced oxidation of cracks formed by I-SCC [57].

\section{3D simulations of a power ramp}

\subsection{Rod and power ramp characteristics}

To show the impact of oxygen redistribution on the thermochemical state of FPs, two power ramps (PR1 and PR2) are considered and simulated with ALCYONE. Details of the experiments are given in Tab. 3. The rods were fabricated by Framatome with the same initially stoichiometric Cr-doped $\mathrm{UO}_{2}$ fuel and $\mathrm{M} 5{ }^{\circledR}$ cladding. They were irradiated in a EDF commercial PWR during 3 cycles and then, re-fabricated as rodlets and ramped by CEA in the OSIRIS test reactor. The burnup of the rodlet in the two tests is slightly different (32 and $38 \mathrm{GWd} / \mathrm{tU})$ but remains close and within the range of critical burnup for PCI analyses [1].

A schematic representation of the ramp tests is given in Figure 10. It starts with a conditioning period that lasts 18 hours. During this period, the sample recovers the thermo-mechanical conditions that it had during its last cycle in a commercial PWR. At the end of the conditioning period ("t0 ramp"), the power starts to increase until it reaches its maximum $(470 \mathrm{~W} / \mathrm{cm})$ at "t0 $\mathrm{HP}$ ". In PR1, the Holding Period (HP) at the maximum Linear Heat Rate (LHR) lasts $12 \mathrm{~h}$ and ends at "t0 HP $+12 \mathrm{~h}$ " (solid line). The PR2 test was performed in the same test reactor OSIRIS [30] and with the same loading sequence except that the power was immediately decreased upon reaching the maximum at "t0 $\mathrm{HP}^{\prime}$ (dashed line). Both fuel rodlets survived the transient undamaged.

The 3D simulation presented hereafter concerns the fuel pellet located at the axial position of the maximum LHR (or PPN for Peak Power Node) in PR1 test. A standard 3D calculation of the base irradiation sequence is first performed with ALCYONE. In the next parts, the analysis of PR1 simulation results will be focused on the $12 \mathrm{~h}$ long plateau where the thermochemical and oxygen transport calculations are both performed. 


\subsection{Pre-ramp fission products distribution in the fuel pellet}

The radial profiles in the fuel pellet fragment of some FPs $(\mathrm{Pu}, \mathrm{Xe}, \mathrm{Mo}, \mathrm{Cs}, \mathrm{Ru}$ and Te), as calculated by PRODHEL, are compared in Figure 11 to EPMA measurements performed after power ramp PR2.

The agreement is good even for FPs in very low quantities such as Te. It may be noticed that no significant release occurred during PR2 due to the prompt decrease of power upon completion of the transient phase. The FPs profiles are representative of the state of the fuel pellet at the end of the nominal irradiation that preceded the power ramp.

\subsection{Evolution of the $\mathrm{O} / \mathrm{M}$ ratio and of the oxygen potential}

The temperature distribution calculated in the fuel pellet fragment at different times of PR1 is illustrated in Figure 12. The maximum temperature is close to 2000 ${ }^{\circ} \mathrm{C}$ at the pellet center. As can be seen, the temperature distribution does not evolve during the HP and has a negligible axial temperature gradient. Oxygen redistribution will therefore be mostly driven by the radial temperature gradient. Figure 13 shows 3D plots of the calculated $\mathrm{O} / \mathrm{M}$ ratio in the fuel fragment at different times during the HP of PR1. Radial profiles of the $\mathrm{O} / \mathrm{M}$ ratio along the mid-pellet plane of the pellet fragment (top of the fragment) are furthermore plotted in Figure 14.

According to performed thermochemical calculations, irradiated fuel is slightly hypo-stoichiometric (as defined in section 3.2) at the beginning of the HP ("t0 HP"). The $\mathrm{O} / \mathrm{M}$ ratio increases along the fuel pellet radius from 1.994 at the pellet center to nearly 2 at the pellet periphery. The formation of internal zirconia during nominal irradiation is not included which would certainly lower the $\mathrm{O} / \mathrm{M}$ ratio at the pellet periphery. During the HP, oxygen transport by thermodiffusion leads to a decrease of the $\mathrm{O} / \mathrm{M}$ ratio (down to $\sim 1.989$ ) at the center of the pellet and to an increase at the pellet periphery (up to 2). Oxygen redistribution kinetics, driven by the diffusion coefficient of Equation 5, is very fast. After 2 minutes, the radial profile of $\mathrm{O} / \mathrm{M}$ ratio is already close to the steady-state profile reached after 12 hours.

Figure 15 shows 3D plots of the calculated oxygen potential in the fuel fragment at different times during the HP of PR1. Radial profiles of the oxygen potential along the mid-pellet plane of the pellet fragment (top of the fragment) are furthermore plotted in Figure 16. As for temperature and the $\mathrm{O} / \mathrm{M}$ ratio, the oxygen potential gradient in the fuel pellet fragment is mainly radial.

It is worth recalling that the temperature distribution during the holding period of the power ramp is quasi-constant, so one may attribute oxygen potential changes to oxygen thermodiffusion only. At the beginning of the HP ("t0 HP"), the oxygen potential follows the temperature gradient, with a maximum of $-300 \mathrm{~kJ} / \mathrm{mol} \mathrm{O}_{2}$ at the pellet center and a minimum of $-450 \mathrm{~kJ} / \mathrm{mol} \mathrm{O}{ }_{2}$ close to the pellet periphery. At the end of the HP, the oxygen potential decreases to $-440 \mathrm{~kJ} / \mathrm{mol} \mathrm{O}_{2}$ at the pellet center while it remains close to $-450 \mathrm{~kJ} / \mathrm{mol} \mathrm{O}_{2}$ at the periphery. The evolution along the radius is however strongly marked with nearly constant oxygen potential up to a relative radius of 0.4 followed by a sudden increase to $-300 \mathrm{~kJ} / \mathrm{mol} \mathrm{O}$ at a relative radius of 0.6. Oxygen potential at the center is within those associated to the 
$\mathrm{Cr}_{(s)} / \mathrm{Cr}_{2} \mathrm{O}_{3(s s)}$ equilibrium [8]. At the pellet periphery, the oxygen potential is very close to the one given by the $\mathrm{Mo}_{(s)} / \mathrm{MoO}_{2(s)}$ equilibrium. The oxygen potential of these redox systems are shown in Figure 16 by dotted and dashed lines respectively.

\subsection{Impact of oxygen transport on metallic oxides}

The decrease of the oxygen potential at the pellet center has important consequences on some of the metallic FPs and added dopants. As expected from the fit of the heat of oxygen transport, chromium oxides are partially reduced. Figure 17 shows the calculated radial profiles of $\mathrm{Cr}$ content in solid solution $\left(\mathrm{Cr}_{2} \mathrm{O}_{3(s s)}\right)$ at the beginning (thick orange curve) and at the end (thick blue curve) of the HP of PR1 compared to EPMA measurements (thin blue curve).

The thin orange curve shows the measured Cr content after PR2 which is similar to the as fabricated content. The evolution of chromium speciation in the 3D simulation of PR1 is shown in Figure 18.

As can be inferred from these results, the sole elevation of the fuel temperature in PR2 during a few tens of seconds did not lead to a reduction of chromium oxide $\left(\mathrm{Cr}_{2} \mathrm{O}_{3(s s)}\right)$ into metallic chromium $\left(\mathrm{Cr}_{(s)}\right)$. According to the performed calculations, oxygen transport by thermodiffusion during the $\mathrm{HP}$ is at the origin of the lower $\mathrm{Cr}$ content in solid solution after PR1. The reduction of chromium soluble oxides into metallic chromium is further confirmed by X-ray images of the central part of the fuel pellet after PR1, see Figure 19. One can find a massive precipitation of metallic $\mathrm{Cr}$ (central image, white spots) which is not associated with oxygen (right image, black spots).

Similar observations are available for molybdenum, see Figure 19 where white spots in the Mo X-ray distribution (left image) are not associated to oxygen (right image, black spots). As stated before, in the thermochemical database of ANGE, Mo is not included in the fluorite solid solution model. One may however estimate the impact of oxygen redistribution by plotting the calculated concentrations of Mo in oxide form $\left(\mathrm{MoO}_{2(s)}\right.$ and $\mathrm{Cs}_{2} \mathrm{MoO}_{4(s)}$ mainly) and that of Mo in metallic form $\left(\mathrm{Mo}_{(s)}\right)$ during the HP of PR1, see Figure 20.

Oxygen transport by thermodiffusion leads to a reduction of $\mathrm{Cs}_{2} \mathrm{MoO}_{4(s, l)}$ at the pellet center and to the precipitation of $\mathrm{Mo}_{(s)}$. EPMA measurements may be compared to the concentrations of these molybdenum species at the end of the HP, see Figure 21.

The blue and orange curves represent the measured Mo content after PR1 and PR2, respectively. As for $\mathrm{Cr}$, the profile after PR2 (similar to the one obtained before the power ramp) shows that the reduction of Mo oxides at the pellet center is not a consequence of the sole temperature elevation during the power transient phase. Oxygen transport by thermodiffusion explains the pronounced increase of metallic Mo during the HP.

Among the other metals, zirconium is a very abundant FP and is found mostly in oxide form in the irradiated fuel pellet, see Figure 22 where EPMA measurements after PR1 are also indicated. Zirconium is found as $\mathrm{ZrO}_{2(s s)}$ in the entire pellet radius except at the periphery where one can also find $\mathrm{BaZrO}_{3(s)}$. Reduction of the zirconium oxide into metallic zirconium would require oxygen potentials lower 
than $-650 \mathrm{~kJ} / \mathrm{mol} \mathrm{O}_{2}$ at the pellet center, which are not reached here in spite of the oxygen redistribution.

\subsection{Noble FGR}

The evolution of noble gas release during the HP of PR1 is illustrated by the 3D plots of xenon released fraction (in \% of the initial inventory) given in Figure 23.

As can be seen, the release of xenon is very small during the first minutes of the HP compared to the end of it. The release begins near the dish in consequence of the lower hydrostatic pressure which favors the expansion of inter-granular fission gas bubbles [6]. At the end of the $12 \mathrm{~h}$ long HP, xenon release from the pellet center reaches $90 \%$. The calculated radial profiles at the beginning and at the end of the HP (along the inter-pellet plane) are compared in Figure 24 to xenon weight fractions from EPMA and Secondary Ion Mass Spectrometry (SIMS) measurements.

The agreement is fair considering the dispersion of experimental measures. It must be recalled that EPMA measurements underestimate the xenon inventory since large gas bubbles are characterized by a peak in the radial profile and are therefore not included in the base line. SIMS measurements are more representative of the total xenon left in the fuel pellet after PR1. Calculations lead to a FGR of around $17 \%$ to be compared with the $8 \%$ measured in the fuel rodlet. The difference stems from the fact that the 3D simulation is local and concerns only the fuel pellet situated at PPN.

\subsection{Iodine release and speciation}

The evolution of iodine release during the HP of PR1 is illustrated by the 3D plots of the iodine released fraction (in $\%$ of the initial inventory) given in Figure 23. The evolution of iodine is similar to that of xenon with a beginning near pellet dishes and a final release of $100 \%$ up to mid pellet radius. The chemical speciation of gaseous iodine must be discussed since it is of importance for PCI failure analyses. Most of the iodine in the fuel pellet fragment leads to the formation of $\mathrm{CsI}_{(g)}$, as can be seen from the 3D plots of Figure 25.

The progressive release of $\mathrm{CsI}_{(g)}$ during the HP explains the lower concentration in the pellet fragment at the end of the power plateau ("t0 HP $+12 \mathrm{~h} "$ ). Apart from $\mathrm{CsI}_{(g)}$, a small part of iodine forms gas species in the pellet $\left(\mathrm{I}_{(g)}, \mathrm{I}_{2(g)}\right.$ and $\left.\mathrm{TeI}_{2(g)}\right)$ that are likely to react with the $\mathrm{Zr}$-cladding to form $\mathrm{ZrI}_{4(g)}$ and hence induce I-SCC if released from the fuel [6]. Figure 25 presents the evolution of their concentration in the fuel pellet during the power ramp PR1. One may see that the concentration of these three iodine gas species is highest at the pellet center at the beginning of the HP ("t0 HP"), meaning that a small proportion of iodine released from the fuel will consist in deleterious gases for the cladding (see Figure 23 where nearly $30 \%$ of the total iodine left the pellet near the dish at t0 HP). Later, after oxygen redistribution, the concentration of these species at the pellet center is around 3 orders of magnitude lower, the maximum concentration being now found between mid-radius and the pellet periphery. Since this part of the pellet does not really contribute to the overall FGR, this means that the release of iodine after a few minutes of HP and in 
consequence of oxygen transport by thermodiffusion will mainly consist in $\operatorname{CsI}_{(g)}$.

\subsection{Cesium release and speciation}

The evolution of cesium release during the HP of PR1 is similar to that of iodine and xenon, as illustrated by the 3D plots of cesium released fraction (in $\%$ of the initial inventory) given in Figure 23. Cesium release at the beginning of the HP ("t0 HP") is lower than that of iodine but increases during the first minutes of the HP and reaches $90 \%$ near the pellet center at the end of the HP. This result is a direct consequence of oxygen redistribution.

Figure 26 shows the evolution of $\mathrm{Cs}_{2} \mathrm{MoO}_{4(s, l)}$ and of gaseous cesium $\left(\mathrm{Cs}_{(g)}+\right.$ $\left.2 \mathrm{Cs}_{2(g)}\right)$ in the $3 \mathrm{D}$ simulation of PR1.

At the beginning of the holding period ("t0 HP"), high quantities of Mo and Cs are bound together as $\mathrm{Cs}_{2} \mathrm{MoO}_{4(s, l)}$. A small fraction of $\mathrm{Cs}$ is in the gas phase, mostly associated to I (around one tenth since there is around ten times more Cs than $\mathrm{I}$ in the fuel pellet at the end of base irradiation). Reduction of $\mathrm{Cs}_{2} \mathrm{MoO}_{4(s, l)}$ at the pellet center in consequence of oxygen redistribution liberates most of the cesium which then forms gaseous compounds (mainly $\mathrm{Cs}_{(g)}$ and $\mathrm{Cs}_{2(g)}$ ) that can be released from the pellet. One clearly see that the reduction of cesium molybdate is associated with the formation of gaseous cesium. Concentration of gaseous cesium is lower at the end of the HP ("t0 HP $+12 \mathrm{~h}$ ") because it has been released from the fuel pellet fragment.

Figure 27 shows the calculated weight fractions of Cs at the end of the HP of PR1 compared to EPMA measurements after PR1 and PR2. Again, PR2 EPMA radial profile is representative of the state of cesium before oxygen redistribution takes place and is very close to the pre-ramp cesium distribution in the pellet. At the end of PR1, the calculated quantity of Cs in the central part of the pellet has considerably decreased which is consistent with EPMA measurements.

\subsection{FGR and CFGR from the fuel pellet fragment}

Figure 28 shows the evolution during the HP of PR1 of the released fractions of cesium, iodine and xenon integrated on the fuel pellet fragment (solid lines).

As was expected from the 3D plots, there is a significant difference between the FGR of Xe-Cs on the one hand and of iodine on the other hand. Iodine release reaches $26 \%$ while Xe and Cs releases reach $17 \%$ and $10 \%$ respectively. An even greater difference in the release of Xe-Cs and I-Te was reported by Baurens [6] from a 3D thermo-chemical-mechanical simulation of a short power ramp. Baurens' results are recovered here if the $3 \mathrm{D}$ simulation of $\mathrm{PR} 1$ is performed without oxygen transport. Iodine and xenon release are not changed by removing oxygen transport but cesium release is. The dashed blue line indicates that cesium release in this case does not exceed $2 \%$ at the end of the HP. This result is a consequence of the cesium speciation in the fuel pellet, where most of cesium remains in stable solid or liquid cesium molybdates and cannot be released from the fuel. 


\subsection{Discussion on PCI criteria}

In a previous paper, the quantity of the so-called "reactive" iodine (i.e., iodine from $\mathrm{I}_{(g)}, \mathrm{I}_{2(g)}$ and $\mathrm{Te}_{2(g)}$ ) released by the pellet during the power transient (from a 3D calculation) was used to estimate the iodine partial pressure in the vicinity of the clad inner wall [6]. It was calculated from the free volume of the fuel pellet (cracks, dishes, chamfer) and of the fuel rod (plenum volume divided by the number of fuel pellets) and also from the temperature of the clad inner wall, assuming ideal gas behavior. It was found that the minimum iodine partial pressure $(60 \mathrm{~Pa})$ identified in out-of-pile mandrel tests to induce I-SCC failures in irradiated clad tubes [58], was exceeded by a factor greater than 10 during the first minute of the HP of a power ramp reaching $520 \mathrm{~W} / \mathrm{cm}$. The $3 \mathrm{D}$ calculation was performed without oxygen redistribution which, as seen above, clearly modifies the fuel thermochemistry during the HP of the power ramp. The iodine partial pressures calculated in the present work are plotted in Figure 29 in function of time (the plot is focused on the first minutes after reaching the maximum power, critical for PCI initiation).

The continuous increase of the partial pressure of "reactive" iodine found in the 3D calculation of Baurens et al. [6] is recovered in the present calculation (dashed green line) when oxygen redistribution is not considered. As explained above, oxygen redistribution modifies the speciation of minor iodine fission gases in the fuel in favor of $\mathrm{CsI}_{(g)}$, which is not expected to react with the cladding. As shown in Figure 25, the concentrations of reactive iodine species $\left(\mathrm{TeI}_{2(g)}, \mathrm{I}_{2(g)}\right.$ and $\left.\mathrm{I}_{(g)}\right)$ decreases in consequence of oxygen transport. It results in a almost stable and reduced iodine partial pressure (solid green curves in Figure 29) compared to the calculation without oxygen redistribution (dashed green curve). This might be consistent with the lack of fuel rod failure by I-SCC in the simulated power ramp PR1.

In the estimation of the iodine partial pressure, the possible contribution of CsI radiolysis [2] [59] (released from the pellet as $\mathrm{CsI}_{(g)}$ and condensed on the fuel pellet cracks' surfaces as $\left.\mathrm{CsI}_{(s)}\right)$ to the "reactive" iodine is neglected. Frégonèse et al. quantified $\mathrm{CsI}_{(s)}$ radiolysis in the inter-pellet zone and in the fuel pellet radial cracks [60], assuming that $\mathrm{CsI}_{(s)}$ decomposition was likely in the first $5 \mu \mathrm{m}$ at the fuel pellet surface. They used the model proposed by Konashi et al. [61] to estimate a potential for dissociation of $20 \%$. If one considers in the presented $3 \mathrm{D}$ calculation with oxygen redistribution that $20 \%$ of the released quantity of $\mathrm{CsI}_{(g)}$ is dissociated, one ends up with a significant and continuous increase of the iodine partial pressure (dashed blue line in Figure 29).

When oxygen redistribution occurs, a large quantity of gaseous cesium is released from the fuel pellet. The recombination of $\mathrm{Cs}_{(g)}$ with "reactive" iodine previously released (including iodine from CsI radiolysis) is thermodynamically favoured. This could reduce the quantity of "reactive" iodine in proportion to the amount of gaseous cesium released from the pellet. Integration of this latter reaction in the estimation of the "reactive" iodine partial pressure leads to a prompt decrease of the latter as soon as oxygen thermodiffusion is activated (blue solid line in Figure 29).

The inclusion of $\mathrm{CsI}_{(s)}$ dissociation in the analysis opens the I-SCC time window (the area marked by the blue solid line in Figure 29). Duration of this window strongly depends on the amount of iodine coming from CsI radiolysis and on the complex sequence of kinetics events at the origin of this phenomenon. Although, it 
is challenging and difficult to experimentally measure, CsI radiolysis seems to be a very important factor in PCI analysis and it requires further investigation.

\section{Conclusions}

The main purpose of this paper was to study the impact of oxygen transport on the chemical state of FPs in a PWR fuel rod during a power ramp and to analyse its impact on PCI failure propensity. In this aim, a complex thermo-chemical-mechanical 3D simulation of a power ramp has been carried out with the fuel performance code ALCYONE which includes local thermochemical equilibrium calculations and oxygen transport at the pellet fragment scale. Calculated radial profiles of $\mathrm{Cr}$ (dopant) and Mo (FP) after the power ramp match the experimental measurements. The reduction of $\mathrm{Cr}$ and Mo oxides into metallic precipitates is recovered in the simulation thanks to oxygen redistribution. The consecutive reduction of cesium molybdate leads to the formation of high quantities of free gaseous cesium that can then be released from the fuel pellet core, in agreement with experimental measurements. Decomposition of cesium molybdate is expected to be of some importance for PCI since iodide gas species released from the fuel in the free volume of the rodlets can form unreactive cesium iodide and hence reduce the potential for Iodine Stress Corrosion Cracking of Zr cladding. These results imply that oxygen transport kinetics might be of importance to improve PCI failure understanding. The calculation presented in this paper uses a very simple model for the chemical diffusion coefficient of oxygen and might therefore be far from reality. Experimental characterization of oxygen thermodiffusion kinetics in irradiated or SIMFUEL fuel is necessary to assess the impact of this phenomenon on PCI failure propensity.

Prospective work include the use of the Thermodynamics of Advanced Fuels - International Database [62], following the recent implementation of the thermochemical equilibrium solver OpenCalphad [63] in ALCYONE [47]. The explicit calculation of point defects (vacancies and oxygen intertitials) in the different phases considered in the database could help improve the modeling of oxygen transport which rely as of today on a fit of the heat of oxygen transport on post-irradiation experimental measurements of $\mathrm{Cr}$ content. This approach is therefore limited to the studied Crdoped fuel. One key point in coupling advanced fuel thermochemistry with oxygen transport including thermodiffusion is the proper formulation of the oxygen mass balance equation [20].

\section{Acknowledgements}

The authors would like to thank FRAMATOME and EDF for their financial and technical support to this work. 


\section{References}

[1] M. H. Piro, D. Sunderland, S. Livingstone, J. Sercombe, W. Revie, A. Quastel, K. Terrani, and C. Judge, "A Review of Pellet-Clad Interaction Behavior in Zirconium Alloy Fuel Cladding," in Reference Module in Materials Science and Materials Engineering, Elsevier, 2017.

[2] B. Lewis, W. Thompson, M. Kleczek, K. Shaheen, M. Juhas, and F. Iglesias, "Modelling of iodine-induced stress corrosion cracking in CANDU fuel," Journal of Nuclear Materials, vol. 408, no. 3, pp. 209-223, 2011.

[3] M. Piro, J. Banfield, K. T. Clarno, S. Simunovic, T. M. Besmann, B. Lewis, and W. Thompson, "Coupled thermochemical, isotopic evolution and heat transfer simulations in highly irradiated $\mathrm{UO}_{2}$ nuclear fuel," Journal of Nuclear Materials, vol. 441, no. 1-3, pp. 240-251, 2013.

[4] M. S. Veshchunov, V. D. Ozrin, V. E. Shestak, V. I. Tarasov, R. Dubourg, and G. Nicaise, "Development of the mechanistic code MFPR for modelling fissionproduct release from irradiated $\mathrm{UO}_{2}$ fuel," Nuclear Engineering and Design, vol. 236, no. 2, pp. 179-200, 2006.

[5] V. Ozrin, "A model for evolution of oxygen potential and stoichiometry deviation in irradiated $\mathrm{UO}_{2}$ fuel," Journal of Nuclear Materials, vol. 419, no. 1, pp. $371-377,2011$.

[6] B. Baurens, J. Sercombe, C. Riglet-Martial, L. Desgranges, L. Trotignon, and P. Maugis, "3D thermo-chemical-mechanical simulation of power ramps with ALCYONE fuel code," Journal of Nuclear Materials, vol. 452, no. 1-3, pp. 578$594,2014$.

[7] C. Nonon, J. C. Menard, S. Lansiart, J. Noirot, S. Martin, G.-M. Decroix, O. Rabouille, C. Delafoy, and B. Petitprez, "PCI behaviour of chromium oxidedoped fuel," in Proc. Symp. on Pellet-clad Interaction in Water Reactor Fuels, Aix-en-Provence, France, 2004.

[8] C. Riglet-Martial, J. Sercombe, J. Lamontagne, J. Noirot, I. Roure, T. Blay, and L. Desgranges, "Experimental evidence of oxygen thermo-migration in PWR $\mathrm{UO}_{2}$ fuels during power ramps using in-situ oxido-reduction indicators," Journal of Nuclear Materials, vol. 480, pp. 32-39, 2016.

[9] C. Sari and G. Schumacher, "Oxygen redistribution in fast reactor oxide fuel," Journal of Nuclear Materials, vol. 61, no. 2, pp. 192-202, 1976.

[10] M. Welland, "3.21 - matter transport in fast reactor fuels," in Comprehensive Nuclear Materials (R. J. Konings, ed.), pp. 629 - 676, Oxford: Elsevier, 2012.

[11] M. Adamson, F. Aitken, S. Evans, and J. Davies, "Oxygen redistribution and its measurement in irradiated oxide fuels," in Proc. IAEA Symp. on thermodynamics of irradiated materials, IAEA-SM-190/54, 1975. 
[12] D. Jadernas, F. Corleoni, A. Puranen, T. P, and M. Granfors, "PCI mitigation using fuel additives," in TopFuel conference, Zurich, Switzerland, 2015.

[13] K. Lassmann, "The oxired model for redistribution of oxygen in nonstoichiometric uranium-plutonium oxides," Journal of Nuclear Materials, vol. 150, no. 1, pp. $10-16,1987$.

[14] J. Ramirez, M. Stan, and P. Cristea, "Simulations of heat and oxygen diffusion in $\mathrm{UO}_{2}$ nuclear fuel rods," Journal of Nuclear Materials, vol. 359, no. 3, pp. 174$184,2006$.

[15] B. Mihaila, M. Stan, J. Ramirez, A. Zubelewicz, and P. Cristea, "Simulations of coupled heat transport, oxygen diffusion, and thermal expansion in $\mathrm{UO}_{2}$ nuclear fuel elements," Journal of Nuclear Materials, vol. 394, no. 2-3, pp. 182189, 2009 .

[16] B. Mihaila, M. Stan, J. Crapps, and D. Yun, "Impact of thermal conductivity models on the coupling of heat transport, oxygen diffusion, and deformation in $(\mathrm{U}, \mathrm{Pu}) \mathrm{O}_{2-x}$ nuclear fuel elements," Journal of Nuclear Materials, vol. 433, no. 1-3, pp. 132-142, 2013.

[17] J. Higgs, B. Lewis, W. Thompson, and Z. He, "A conceptual model for the fuel oxidation of defective fuel," Journal of Nuclear Materials, vol. 366, no. 1-2, pp. 99-128, 2007.

[18] M. Welland, W. Thompson, B. Lewis, and D. Manara, "Computer simulations of non-congruent melting of hyperstoichiometric uranium dioxide," Journal of Nuclear Materials, vol. 385, no. 2, pp. 358-363, 2009.

[19] T. M. Besmann, J. W. McMurray, B. G. Gaston, S. Simunovic, and M. A. Piro, "Modeling thermochemistry of fuel and coupling to fuel performance codes," in Top Fuel conference, Boise, Idaho, USA, 2016.

[20] S. Simunovic, J. McMurray, T. Besmann, E. Moore, and M. Piro, "Coupled mass and heat transport models for nuclear fuels using thermodynamic calculations," tech. rep., Oak Ridge National Laboratory, ORNL/TM-2018/2, 2017.

[21] B. Michel, C. Nonon, J. Sercombe, F. Michel, and V. Marelle, "Simulation of pellet-cladding interaction with the pleiades fuel performance software environment," Nuclear Technology, vol. 182, no. 2, pp. 124-137, 2013.

[22] V. Marelle, P. Goldbronn, C. Introini, S. Bernaud, A. Bouloré, M. Casella, C. Fillaux, J. Julien, K. Mer-Nkonga, and L. Noirot, "Validation of PLEIADES/ALCYONE 2.0 fuel performance code," in Water Reactor Fuel Performance Meeting, Jeju Island, Korea, 2017.

[23] L. Noirot tech. rep., CEA Cadarache, 2018.

[24] OCDE/NEA, "JANIS 4.0 Java-based Nuclear Data Information System." https://www . oecd-nea.org/janis/. 
[25] M. Vidal, R. Eschbach, A. Launay, C. Binet, and J.-F. Thro, "CESAR 5.3: An industrial tool for nuclear fuel and waste characterization with associated qualification," in Waste Management, Phoenix, Arizona, USA, 2012.

[26] A. Santamarina, D. Bernard, P. Blaise, P. Leconte, R. Le Tellier, C. VaglioGaudard, and J.-F. Vidal, "APOLLO 2.8: a validated code package for PWR neutronics calculations," in 4th Topical Meeting on Advances in Nuclear Fuel Management, vol. 2, 2009.

[27] B. Michel, J. Sercombe, C. Nonon, and O. Fandeur, "3.22 - Modeling of pellet cladding interaction," in Comprehensive Nuclear Materials (R. J. Konings, ed.), pp. $677-712$, Oxford: Elsevier, 2012.

[28] J. Sercombe, I. Aubrun, and C. Nonon, "Power ramped cladding stresses and strains in 3D simulations with burnup-dependent pellet-clad friction," Nuclear Engineering and Design, vol. 242, pp. 164-181, 2012.

[29] CAST3M. http://www-cast3m.cea.fr/.

[30] C. Mougel, B. Verhaeghe, C. Verdeau, S. Lansiart, S. Beguin, and B. Julien, "Power ramping in the Osiris reactor: database analysis for standard $\mathrm{UO}_{2}$ fuel with Zy-4 cladding," in Proc. Symp. on Pellet-clad Interaction in Water Reactor Fuels, Aix-en-Provence, France, 2005.

[31] L. Noirot, "Margaret: A comprehensive code for the description of fission gas behavior," Nuclear Engineering and Design, vol. 241, no. 6, pp. 2099-2118, 2011.

[32] P. Garcia, J. P. Piron, and D. Baron, "A model for the oxygen potential of oxide fuels at high burnup," in Proc. Symp. on Water reactor fuel element modelling at high burnup and its Experimental Support, Windermere, UK, 1994.

[33] G. Eriksson, "Thermodynamic studies of high-temperature equilibria. 12. solgasmix, a computer-program for calculation of equilibrium compositions in multiphase systems," Chemica Scripta, vol. 8, no. 3, pp. 100-103, 1975.

[34] T. B. Lindemer and T. M. Besmann, "Chemical thermodynamic representation of $\mathrm{UO}_{2 \pm x}$," Journal of Nuclear Materials, vol. 130, pp. 473 - 488, 1985.

[35] T. M. Besmann and T. B. Lindemer, "Chemical thermodynamic representations of $\mathrm{PuO}_{2-x}$ and $\mathrm{U}_{1-z} \mathrm{Pu}_{z} \mathrm{O}_{w}$," Journal of Nuclear Materials, vol. 130, pp. $489-$ 504, 1985.

[36] B. Lindemer and J. Brynestad, "Review and chemical thermodynamic representation of $\mathrm{U}_{1-z} \mathrm{Ce}_{z} \mathrm{O}_{2 \pm x}$ and $\mathrm{U}_{1-z} \mathrm{Ln}_{z} \mathrm{O}_{2 \pm x} ; \mathrm{Ln}=\mathrm{Y}, \mathrm{La}, \mathrm{Nd}, \mathrm{Gd}$," Journal of the American Ceramic Society, vol. 69, no. 12, pp. 867-876, 1986.

[37] J.-C. Dumas, Etude des conditions de formation du joint oxyde-gaine dans les combustibles des réacteurs à neutrons rapides : observations et proposition d'un modèle de comportement des produits de fission volatils. $\mathrm{PhD}$ thesis, Institut National Polytechnique, Grenoble, France, 1995. 
[38] C. Riglet-Martial, P. Martin, D. Testemale, C. Sabathier-Devals, G. Carlot, P. Matheron, X. Iltis, U. Pasquet, C. Valot, C. Delafoy, et al., "Thermodynamics of chromium in $\mathrm{UO}_{2}$ fuel: A solubility model," Journal of Nuclear Materials, vol. 447, no. 1-3, pp. 63-72, 2014.

[39] D. R. Olander, "Fundamental aspects of nuclear reactor fuel elements," tech. rep., California Univ., Berkeley (USA). Dept. of Nuclear Engineering, 1976.

[40] M. Piro, M. Welland, and M. Stan, "On the interpretation of chemical potentials computed from equilibrium thermodynamic codes," Journal of Nuclear Materials, vol. 464, pp. 48 - 52, 2015.

[41] M. Bober and G. Schumacher, "Material transport in the temperature gradient of fast reactor fuels," in Advances in Nuclear Science and Technology, Volume 7, pp. 121-179, Elsevier, 1973.

[42] C. Guéneau, M. Baichi, D. Labroche, C. Chatillon, and B. Sundman, "Thermodynamic assessment of the uranium-oxygen system," Journal of Nuclear Materials, vol. 304, no. 2, pp. $161-175,2002$.

[43] C. Walker, V. Rondinella, D. Papaioannou, S. Van Winckel, W. Goll, and R. Manzel, "On the oxidation state of $\mathrm{UO}_{2}$ nuclear fuel at a burn-up of around $100 \mathrm{MWd} / \mathrm{kgHM}$," Journal of nuclear materials, vol. 345, no. 2-3, pp. 192-205, 2005.

[44] W. Thompson, B. Lewis, E. Corcoran, M. Kaye, S. White, F. Akbari, Z. He, R. Verrall, J. Higgs, D. Thompson, et al., "Thermodynamic treatment of uranium dioxide based nuclear fuel," International Journal of Materials Research, vol. 98, no. 10, pp. 1004-1011, 2007.

[45] K. Une and M. Oguma, "Oxygen potentials of $\mathrm{UO}_{2}$ fuel simulating high burnup," Journal of Nuclear Science and Technology, vol. 20, no. 10, pp. 844-851, 1983.

[46] H. Loukusa, T. Ikonen, V. Valtavirta, and V. Tulkki, "Thermochemical modeling of nuclear fuel and the effects of oxygen potential buffers," Journal of Nuclear Materials, vol. 481, pp. 101-110, 2016.

[47] C. Introini, J. Sercombe, J. Dumas, P. Goldbronn, and V. Marelle, "Integration of the OpenCalphad thermo-chemical solver in PLEIADES/ALCYONE fuel performance code," Oral presentation at the NuMat 2018 conference, Seattle, 2018.

[48] C. Guéneau, C. Chatillon, and B. Sundman, "Thermodynamic modelling of the plutonium-oxygen system," Journal of Nuclear Materials, vol. 378, no. 3, pp. 257-272, 2008.

[49] T. M. Besmann, J. W. McMurray, and S. Simunovic, "Application of thermochemical modeling to assessment/evaluation of nuclear fuel behavior," Calphad, vol. 55, pp. $47-51,2016$. 
[50] J. Janek and H. Timm, "Thermal diffusion and soret effect in (U, Me) $\mathrm{O}_{2+\delta}$ : the heat of transport of oxygen," Journal of Nuclear Materials, vol. 255, no. 2-3, pp. 116-127, 1998.

[51] B. Baurens, Couplages thermo-chimie-mécaniques dans le dioxyde d'uranium: application à l' intéraction pastille-gaine. $\mathrm{PhD}$ thesis, Université Aix-Marseille, 2014.

[52] C. Berthinier, C. Rado, C. Chatillon, and F. Hodaj, "Thermodynamic assessment of oxygen diffusion in non-stoichiometric $\mathrm{UO}_{2 \pm x}$ from experimental data and frenkel pair modeling," Journal of Nuclear Materials, vol. 433, no. 1-3, pp. 265-286, 2013.

[53] E. Moore, C. Guéneau, and J.-P. Crocombette, "Diffusion model of the nonstoichiometric uranium dioxide," Journal of Solid State Chemistry, vol. 203, pp. 145-153, 2013.

[54] E. Moore, C. Guéneau, and J.-P. Crocombette, "Oxygen diffusion model of the mixed (U, Pu) $\mathrm{O}_{2 \pm x}$ : Assessment and application," Journal of Nuclear Materials, vol. 485, pp. 216-230, 2017.

[55] P. Koukkari, R. Pajarre, and K. Hack, "Constrained gibbs energy minimisation," International journal of materials research, vol. 98, no. 10, pp. 926-934, 2007.

[56] J.-B. Minne, L. Desgranges, V. Optasanu, N. Largenton, L. Raceanu, and T. Montesin, "Specific aspects of internal corrosion of nuclear clad made of zircaloy," in Defect and Diffusion Forum, vol. 323, pp. 227-232, Trans Tech Publ, 2012.

[57] J. Davies, E. Hoshi, and D. Zimmerman, "Ramp test behavior of high $\mathrm{O} / \mathrm{U}$ fuel," Journal of nuclear materials, vol. 270, no. 1-2, pp. 87-95, 1999.

[58] C. Anghel, A.-M. Holston, G. Lysell, S. Karlsson, R. Jakobsson, J. Flygare, S. Mahmood, D. Le Boulch, and I. Arimescu, "Experimental and finite element modeling parametric study for iodine-induced stress corrosion cracking of irradiated cladding," TopFuel conference, Orlando, US, 2010.

[59] K. Konashi, K. Kamimura, and Y. Yokouchi, "Estimation of irradiation induced iodine pressure in an LWR fuel rod," Journal of Nuclear Materials, vol. 125, pp. 244-247, 1984.

[60] M. Frégonèse, G. Delette, G. Ducros, and F. Lefebvre, "Amount of iodine responsible for I-SCC of Zircaloy-4 in PCI-conditions: recoil-implanted and thermally released iodine," Nuclear Engineering and Design, vol. 186, no. 3, pp. 307 - 322, 1998.

[61] K. Konashi, Y. Shiokawa, and H. Kayano, "Simulation of CsI decomposition in fuel cladding gap," Journal of nuclear materials, vol. 232, no. 2-3, pp. 181-185, 1996. 
[62] https://www. oecd-nea.org/science/taf-id/.

[63] B. Sundman, U. Kattner, M. Palumbo, and S. Fries, "OpenCalphad - a free thermodynamic software," Integrating Materials and Manufacturing Innovation, vol. 4, no. 1, pp. 1-15, 2015.

[64] R. Woodley, "Oxygen potentials of plutonia and urania-plutonia solid solutions," Journal of Nuclear Materials, vol. 96, no. 1, pp. 5 - 14, 1981.

[65] T. L. Markin and E. J. Mc Iver, Plutonium 1965. Chapman and Hall, London, 1979.

[66] K. Hagemark and M. Broli, "Equilibrium oxygen pressures over solid solutions of urania-yttria and urania-lanthana at 1100 to $1400^{\circ} \mathrm{C}$," Journal of the American Ceramic Society, vol. 50, no. 11, pp. 563-567.

[67] T. Fujino, "Thermodynamics of fluorite type solid solutions containing plutonium, lanthanide elements or alkaline earth metals in uranium dioxide host lattices," Journal of Nuclear Materials, vol. 154, no. 1, pp. 14 - 24, 1988.

[68] T. B. Lindemer and A. L. Sutton Jr, "Study of nonstoichiometry of solid $\mathrm{U}_{1-z} \mathrm{Gd}_{z} \mathrm{O}_{2 \pm x}$, " Journal of the American Ceramic Society, vol. 71, no. 7, pp. 553-561, 1988.

[69] K. S. Kim, J. H. Yang, K. W. Kang, K. W. Song, and G. M. Kim, "Measurement of $\mathrm{Gd}$ content in (U,Gd) $\mathrm{O}_{2}$ using thermal gravimetric analysis," Journal of Nuclear Materials, vol. 325, pp. 129 - 133, 2004.

[70] K. Une and M. Oguma, "Oxygen potentials of (U, Gd) $\mathrm{O}_{2 \pm x}$ solid solutions in the temperature range $1000-1500^{\circ} \mathrm{C}, "$ Journal of Nuclear Materials, vol. 115, no. 1, pp. 84-90, 1983. 


\section{Figures}
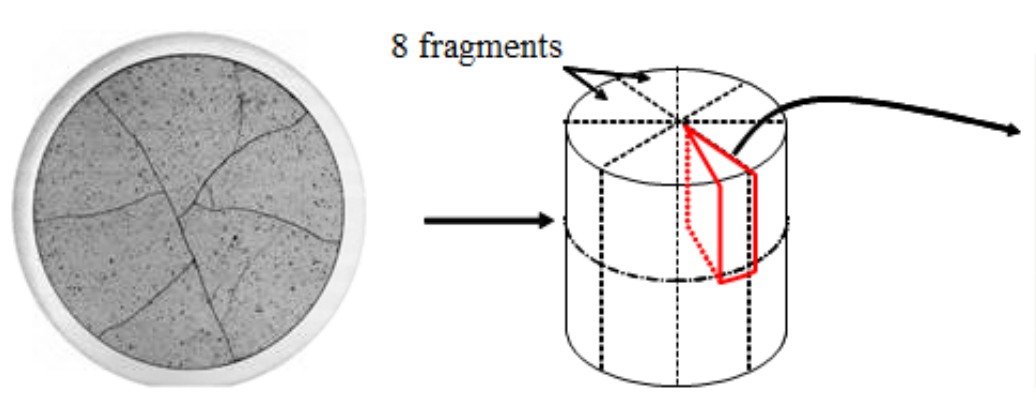

Typical crack network in a fuel pellet at the end of base irradiation

Mid-Pellet plane

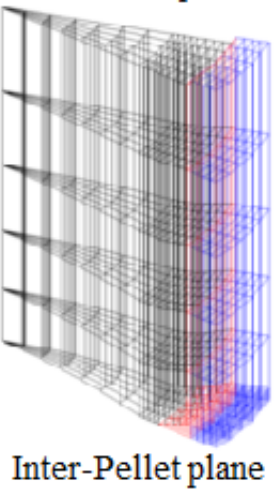

Figure 1: 3D scheme of ALCYONE. A fuel pellet is divided in 8 identical fragments in order to account for the crack network that forms during nominal irradiation. 

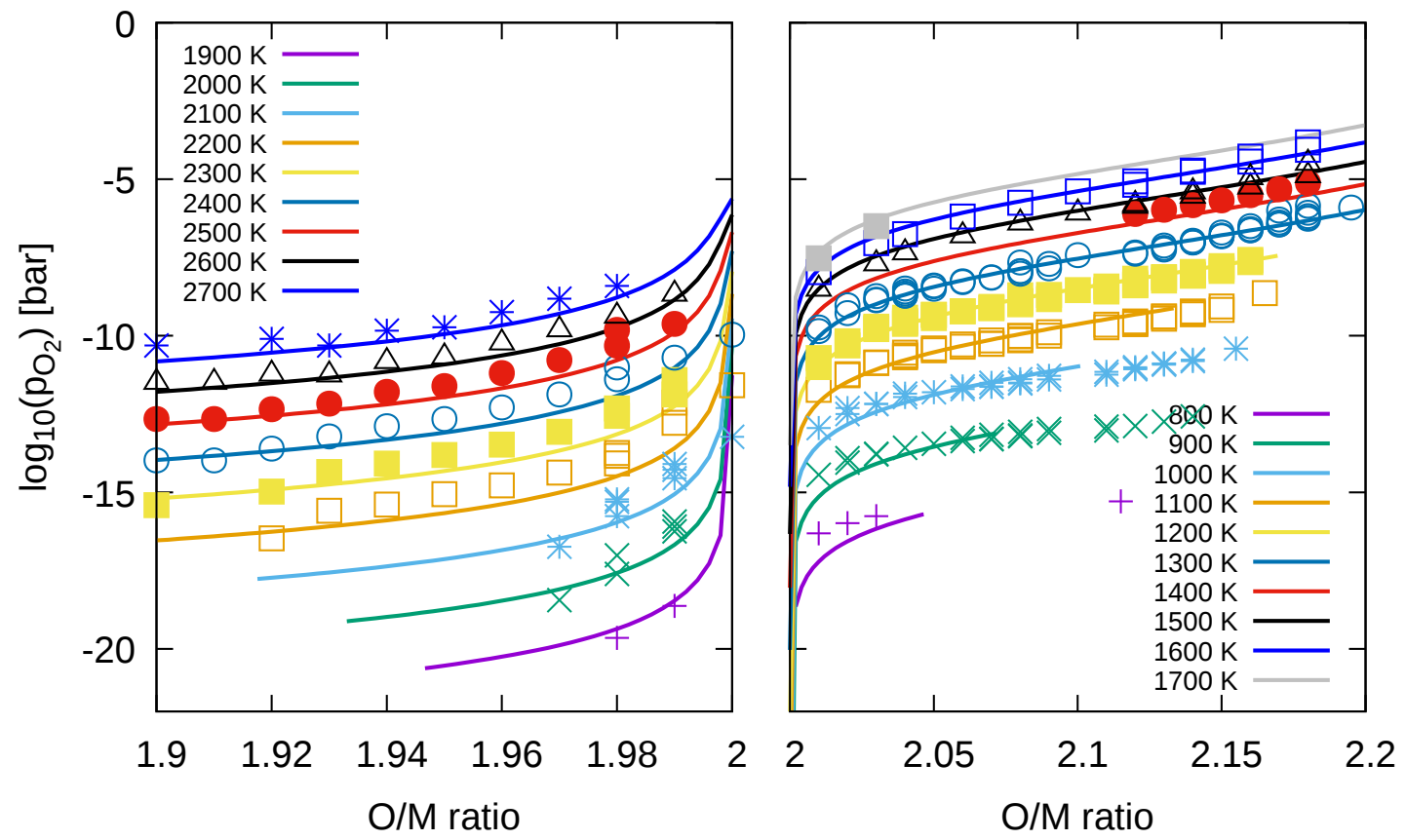

Figure 2: Experimental data gathered by Guéneau et al. [42] for $\mathrm{UO}_{2 \pm x}$ (symbols) compared to calculated oxygen partial pressures and O/M ratio with ANGE (lines).

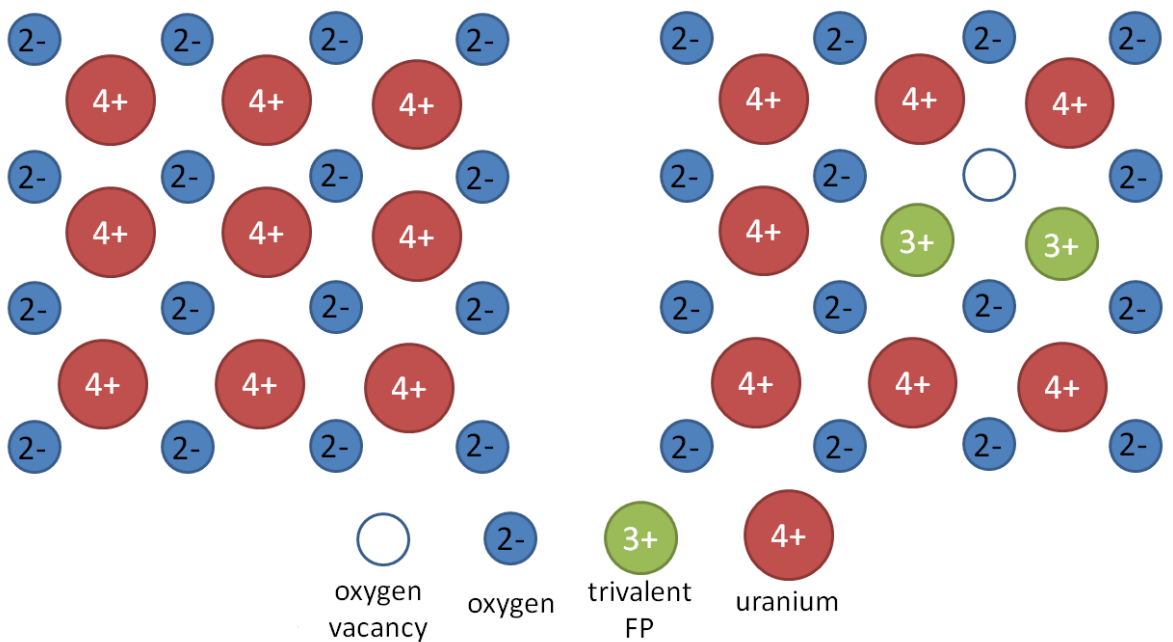

Figure 3: Schematic representation of $\mathrm{UO}_{2}$ lattice when a trivalent $\mathrm{FP}$ replaces a $\mathrm{U}$ atom after fission (adapted from Olander [39], chapter 12, Figure 12.8). Left figure: perfect $\mathrm{UO}_{2}$ lattice. Right figure: irradiated fuel. 

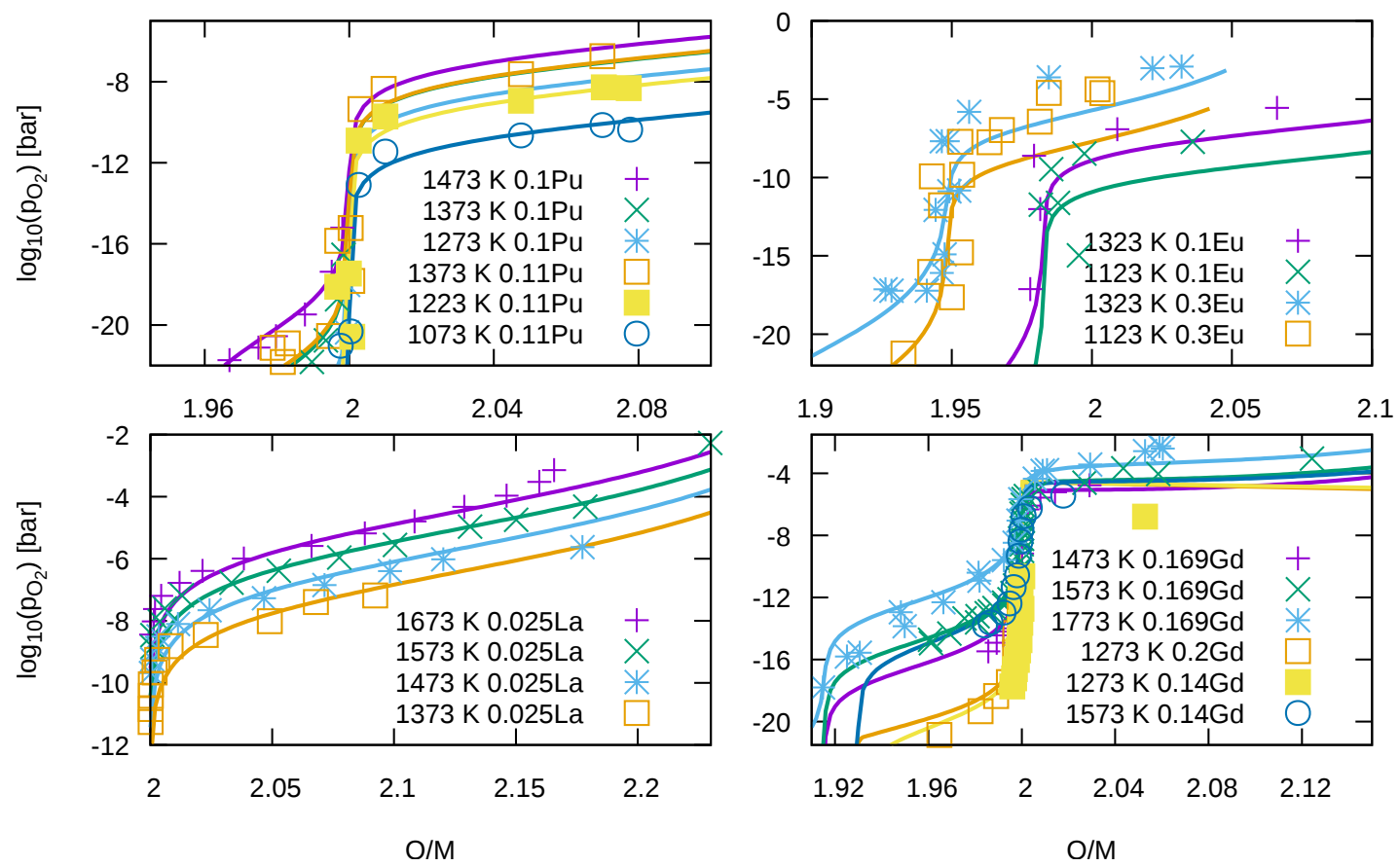

Figure 4: Measured oxygen partial pressure in function of the $\mathrm{O} / \mathrm{M}$ ratio of $\mathrm{U}_{1-z} \operatorname{Ln}_{z} \mathrm{O}_{2 \pm x}$ fuels with $\mathrm{Ln}=\mathrm{Pu}[64,65], \mathrm{Ln}=\mathrm{La}[66], \mathrm{Ln}=\mathrm{Eu}[67]$ and $\mathrm{Ln}=\mathrm{Gd}$ [68-70] compared to the ANGE calculations (lines). 


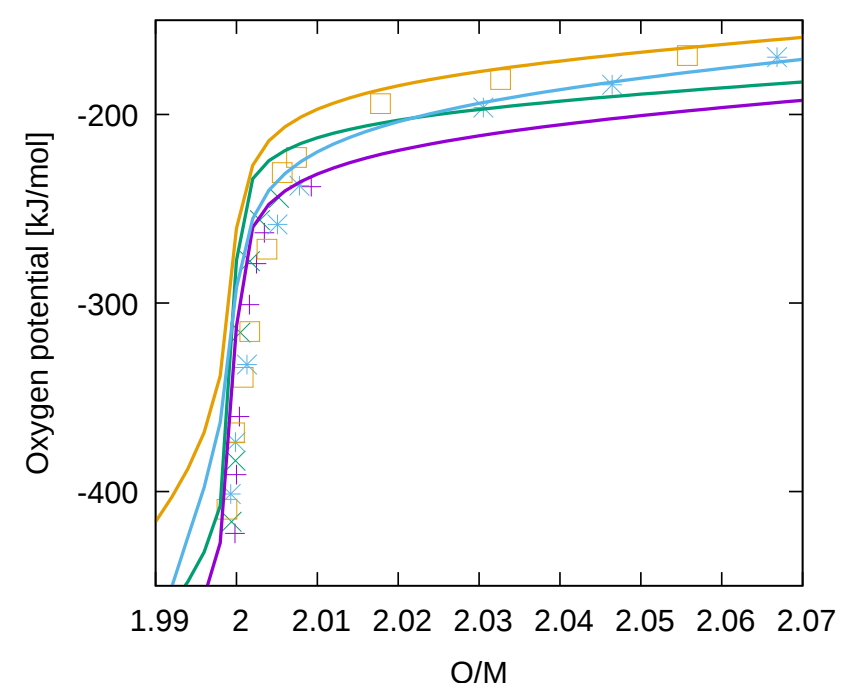

5 at $\% 1000^{\circ} \mathrm{C}$

5 at $\% 1300^{\circ} \mathrm{C}$

10 at $\% 1300^{\circ} \mathrm{C}$

Figure 5: Oxygen potential $\Delta G_{\mathrm{O}_{2}}$ of SIMFUELs (burnups of 5 and 10 at\%) as measured by Une and Oguma [45] (symbols) compared to ANGE calculations (lines).

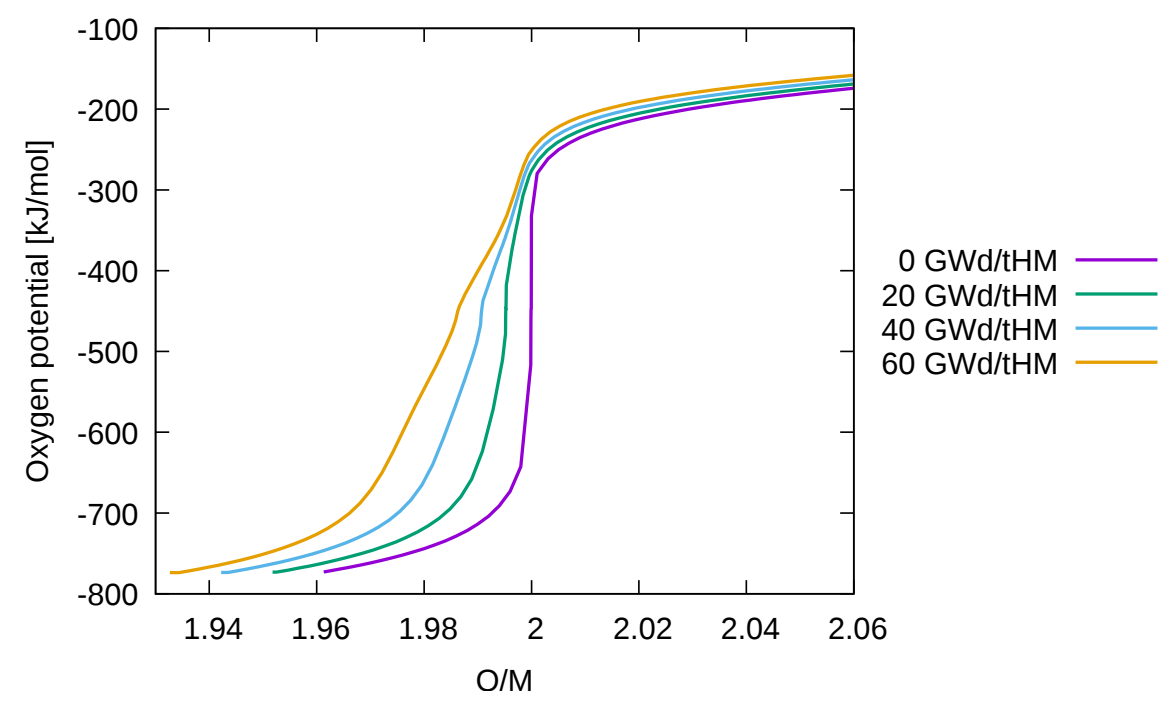

Figure 6: The oxygen potential $\Delta G_{\mathrm{O}_{2}}$ of an initially stoichiometric Cr-doped $\mathrm{UO}_{2}$ fuel in function of the $\mathrm{O} / \mathrm{M}$ ratio at $1500{ }^{\circ} \mathrm{C}$ and at different burnups. Calculated with ANGE. Elemental composition is shown in Tab. 2. 


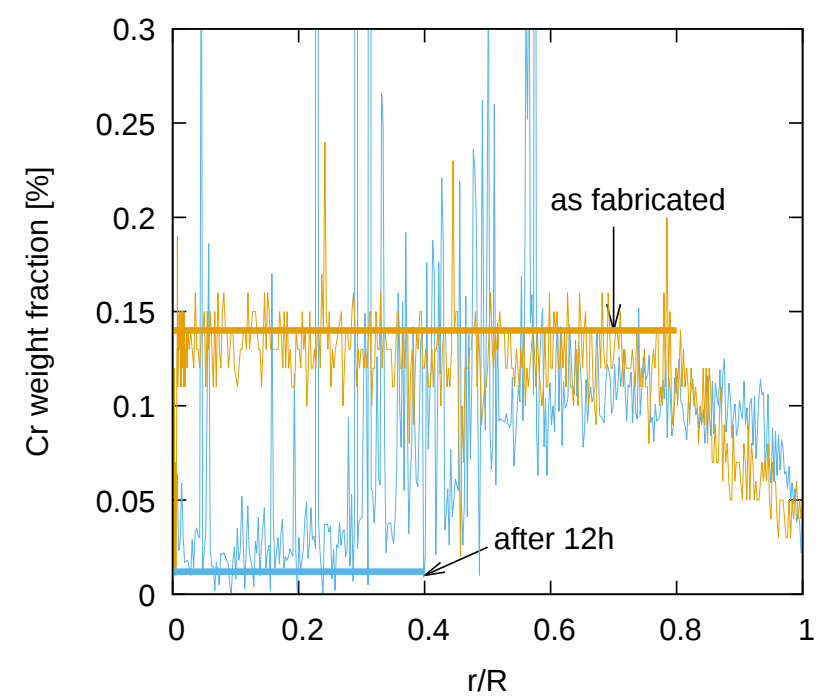

after $12 \mathrm{~h}$

as fabricated

Figure 7: Evolution of chromium weight fraction in a $\mathrm{UO}_{2}$ fuel pellet during a $12 \mathrm{~h}$ long holding period at $470 \mathrm{~W} / \mathrm{cm}$, from EPMA measurements.

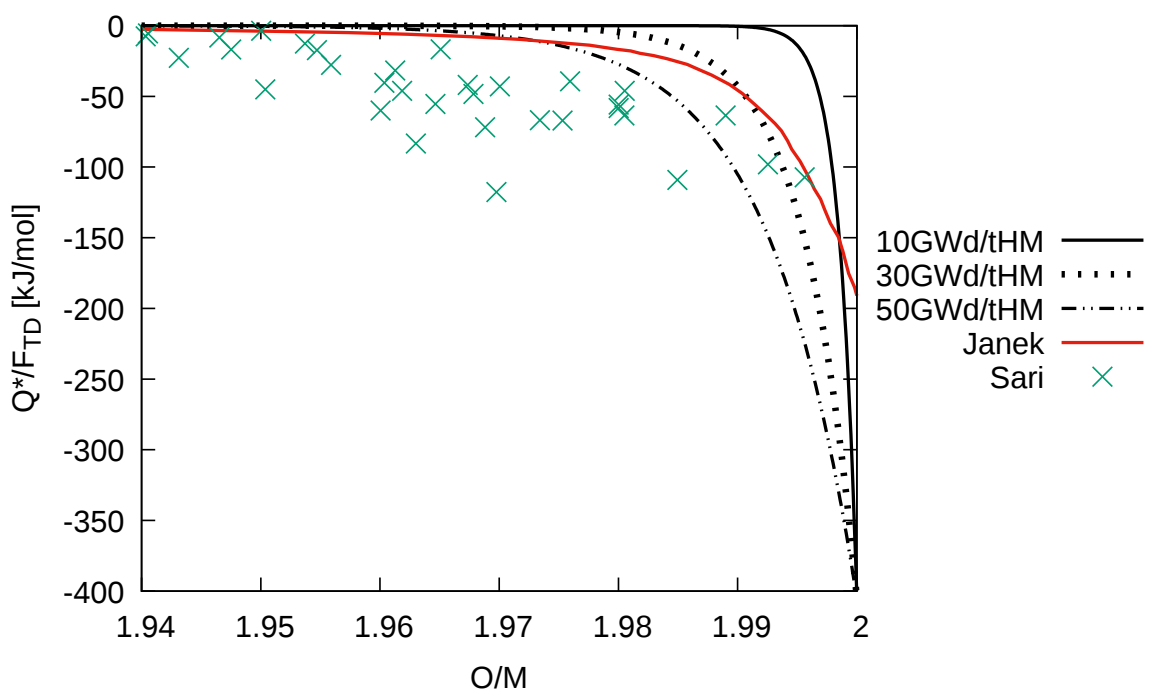

Figure 8: Heat of oxygen transport in $\mathrm{UO}_{2}$ fuels irradiated up to different burnups in function of the $\mathrm{O} / \mathrm{M}$ ratio compared to the model proposed by Janek [50], based on a reassessment of Sari's measures [9]. 


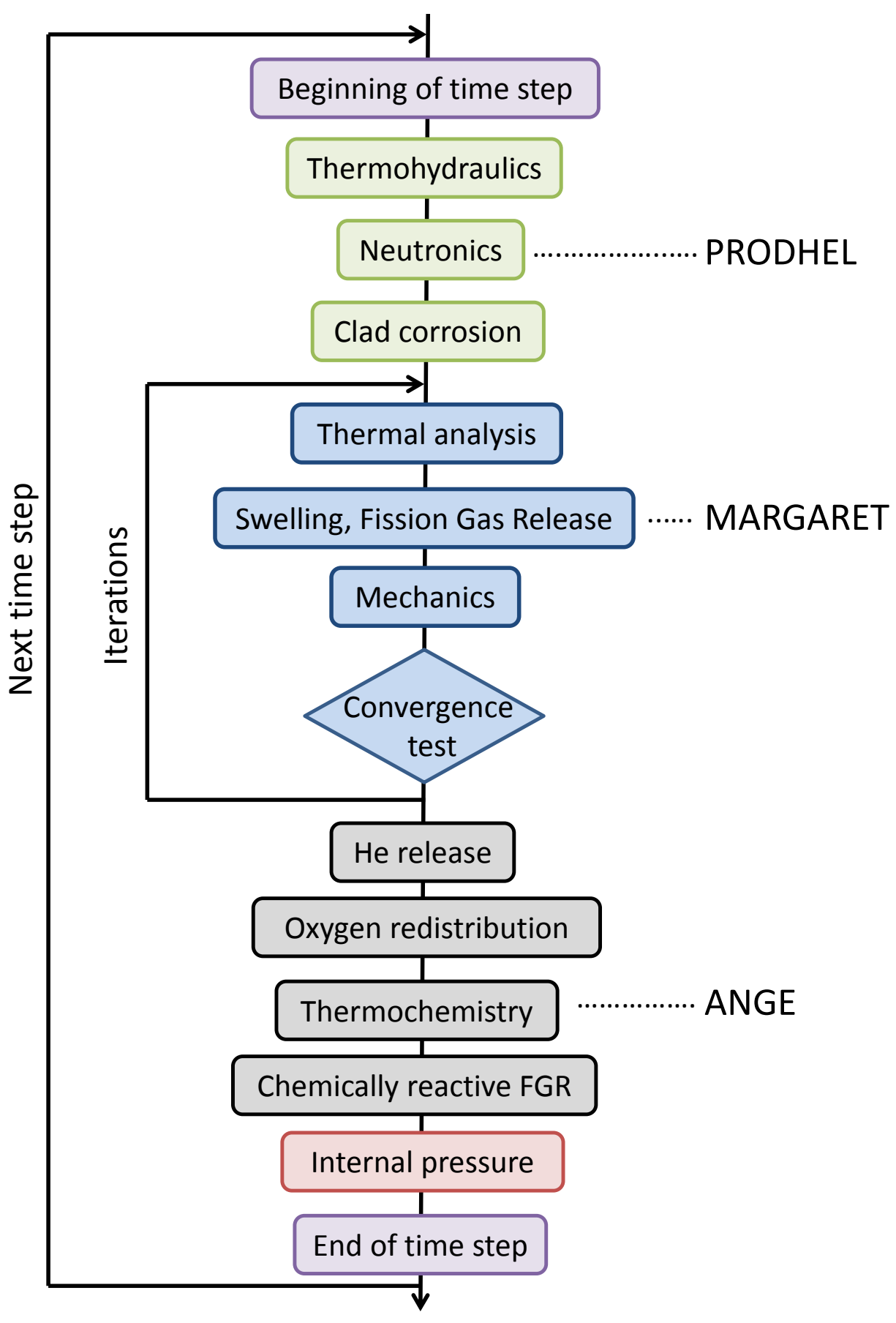

Figure 9: Schematic representation of iterative loops and models called during a simulation performed with the fuel performance code ALCYONE. 


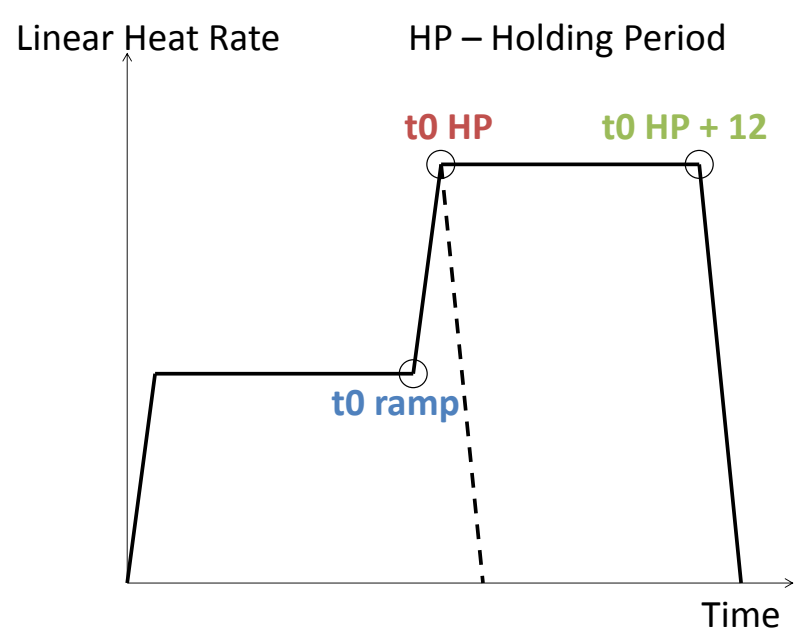

Figure 10: Schematic representation of the power ramp tests. The part until "t0 HP" is common for both ramps. The solid line starting at "t0 HP" is for PR1 and the dashed one is for PR2. 


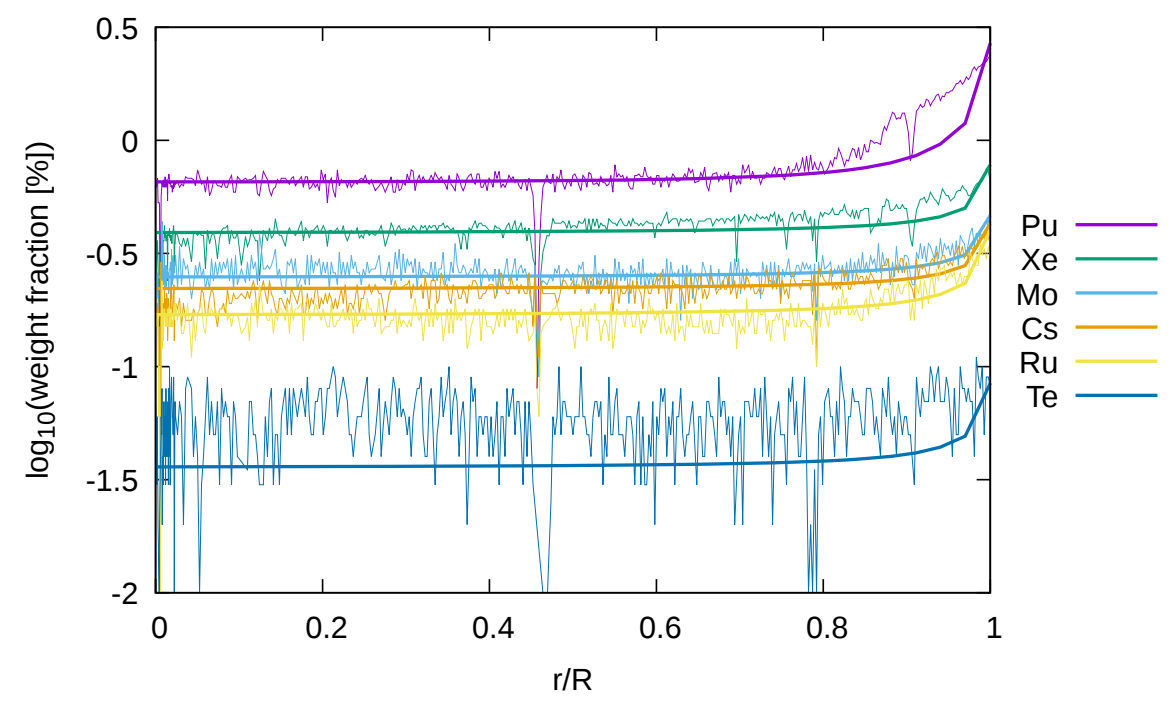

Figure 11: Weight fractions of some FPs calculated with PRODHEL (thick lines) compared to EPMA measurements (thin lines) after the PR2 test (see Tab. 3).
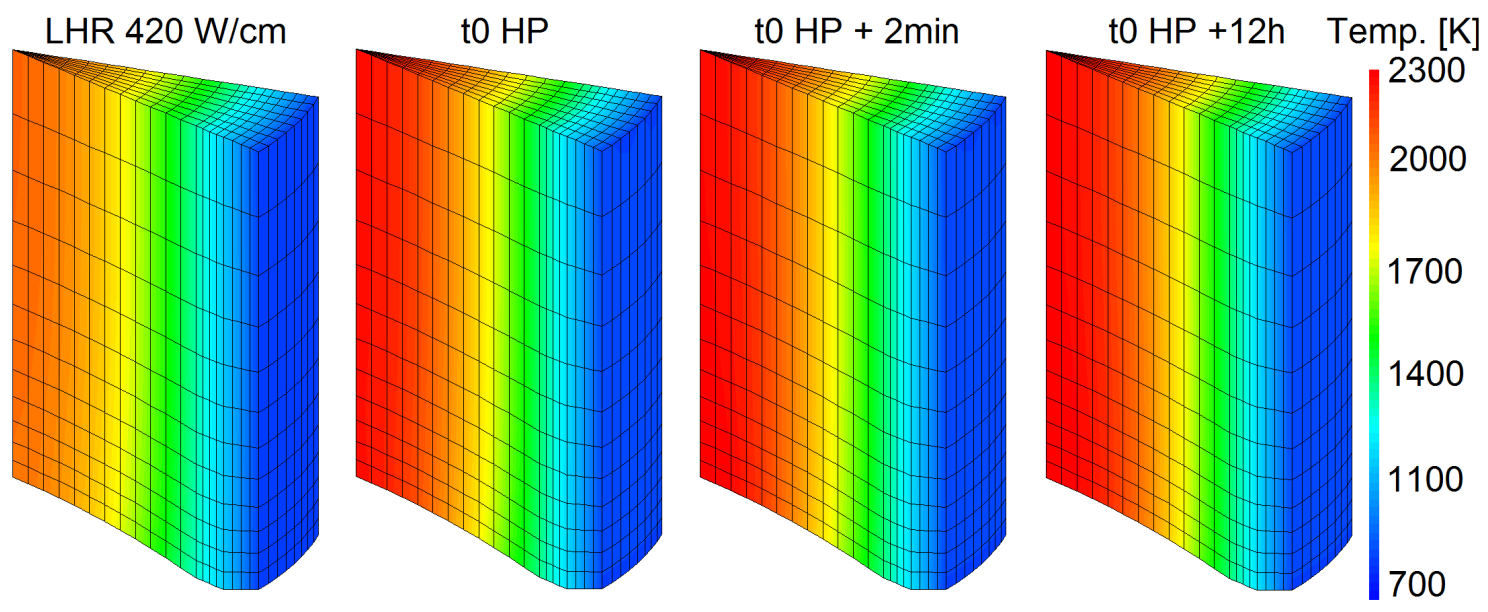

Figure 12: Calculated temperatures $[\mathrm{K}]$ in the fuel fragment at different times during the power ramp PR1. 

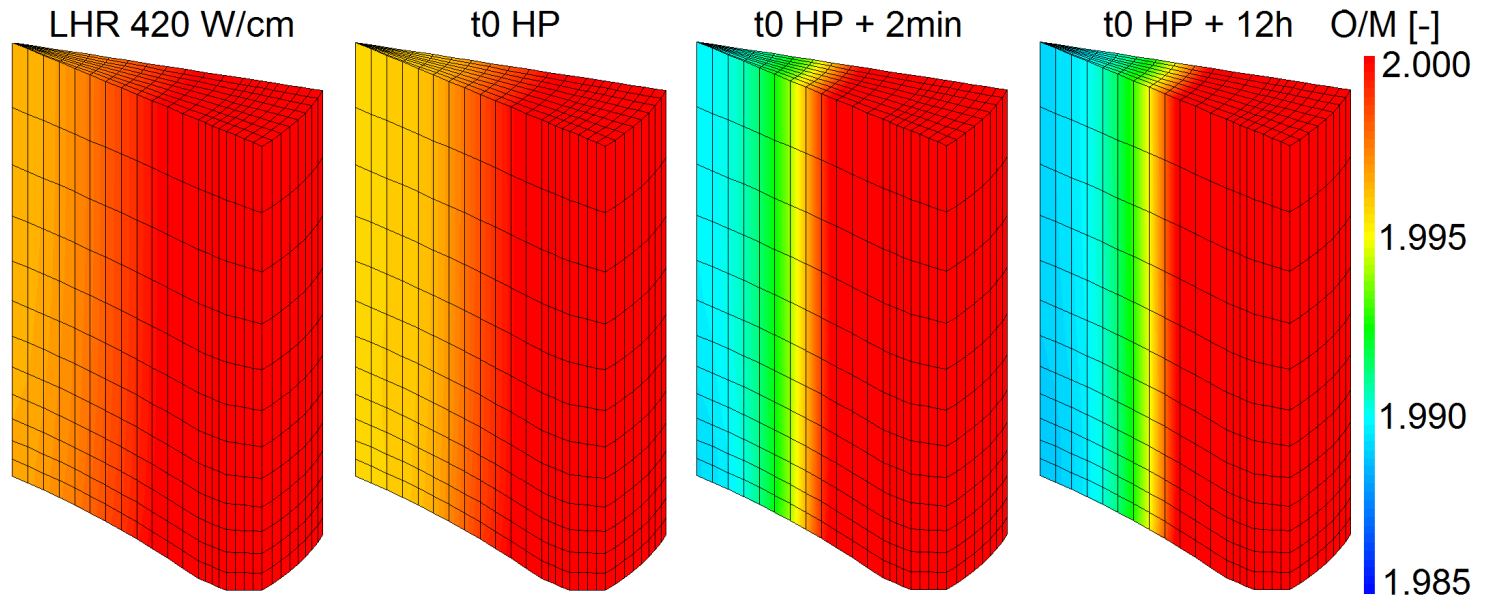

Figure 13: Calculated $\mathrm{O} / \mathrm{M}$ ratios [-] in the fuel fragment at different times during the power ramp PR1. The top plane of this fragment is the mid-pellet plane and the bottom plane is the inter-pellet plane where the dish can be seen.

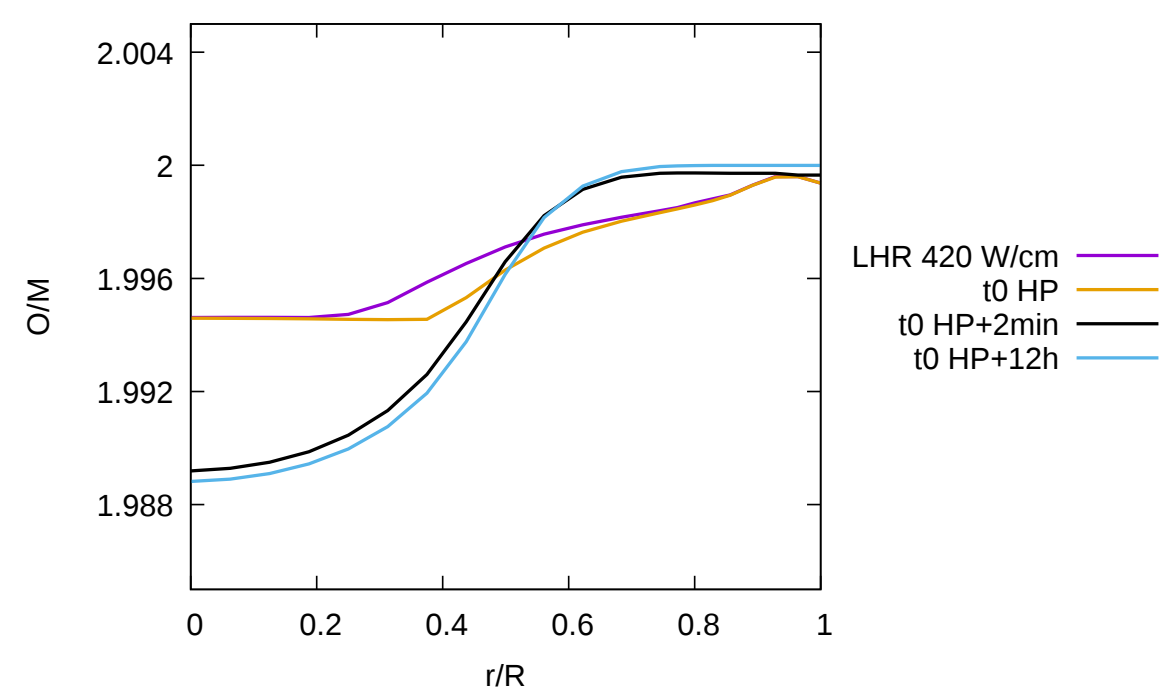

Figure 14: Calculated $\mathrm{O} / \mathrm{M}$ radial profiles along the mid-pellet plane of the pellet fragment at different times during the power ramp PR1. 

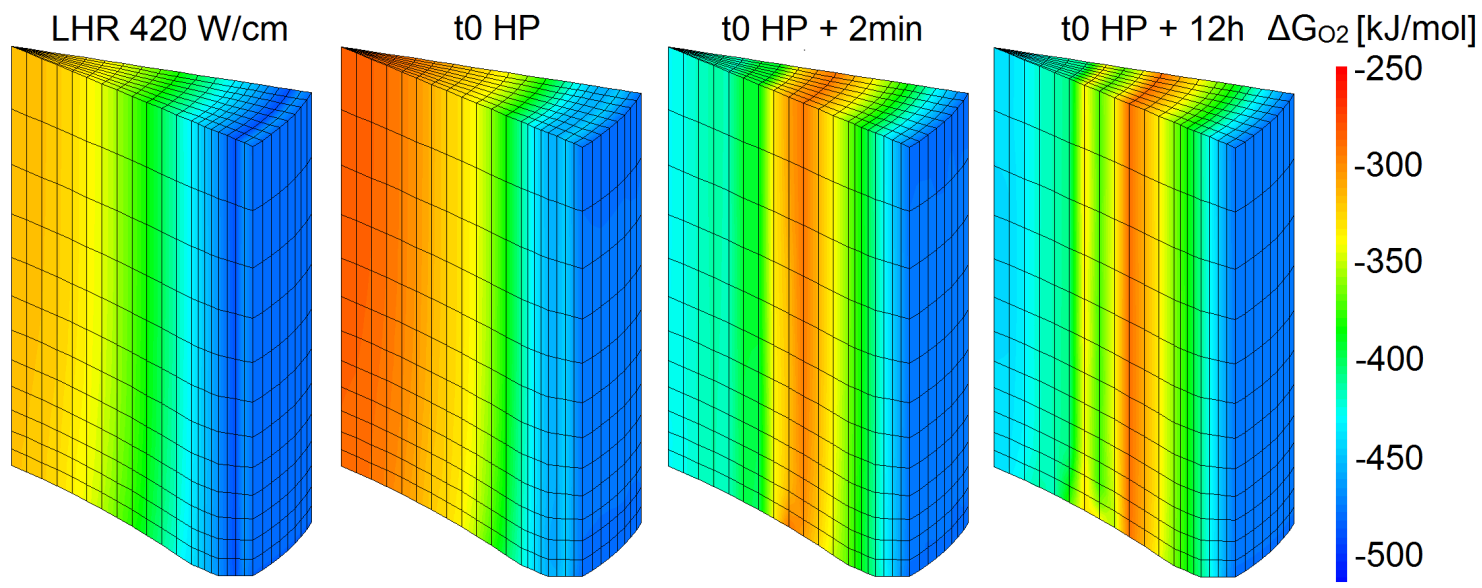

Figure 15: Calculated oxygen potentials $\Delta G_{\mathrm{O}_{2}}\left[\mathrm{~kJ} / \mathrm{mol} \mathrm{O}_{2}\right]$ in the fuel fragment at different times during power ramp PR1.
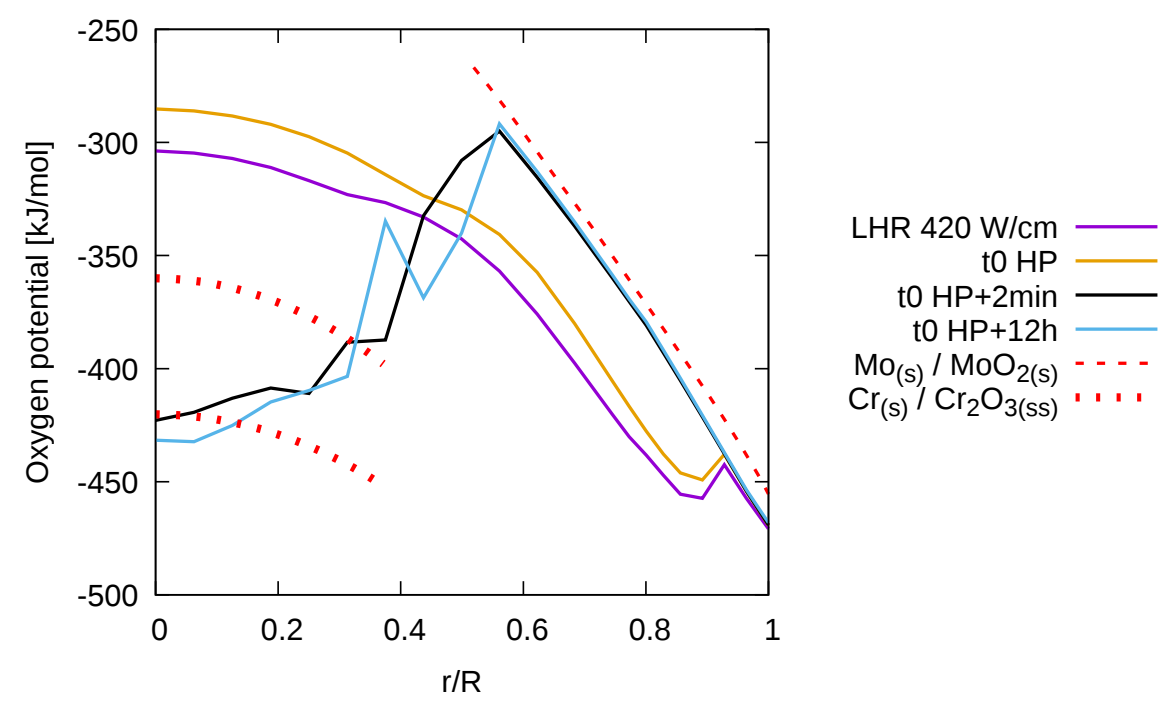

Figure 16: Calculated radial profiles of oxygen potential $\Delta G_{\mathrm{O}_{2}}$ along the mid-pellet radius at different times during power ramp PR1. The red dashed line shows the oxygen potential given by the $\mathrm{Mo}_{(s)} / \mathrm{MoO}_{2(s)}$ redox system. The dotted lines give the oxygen potential associated with the $\mathrm{Cr}_{2} \mathrm{O}_{3(s s)} / \mathrm{Cr}_{(s)}$ redox system: top line for a Cr-dopant completely dissolved in $\mathrm{UO}_{2}$ (0.14 wt\%, see Figure 7, as fabricated), bottom line corresponding to a residual Cr-solubility of $0.01 \%$ (see Figure 7 , after $12 \mathrm{~h})$. 

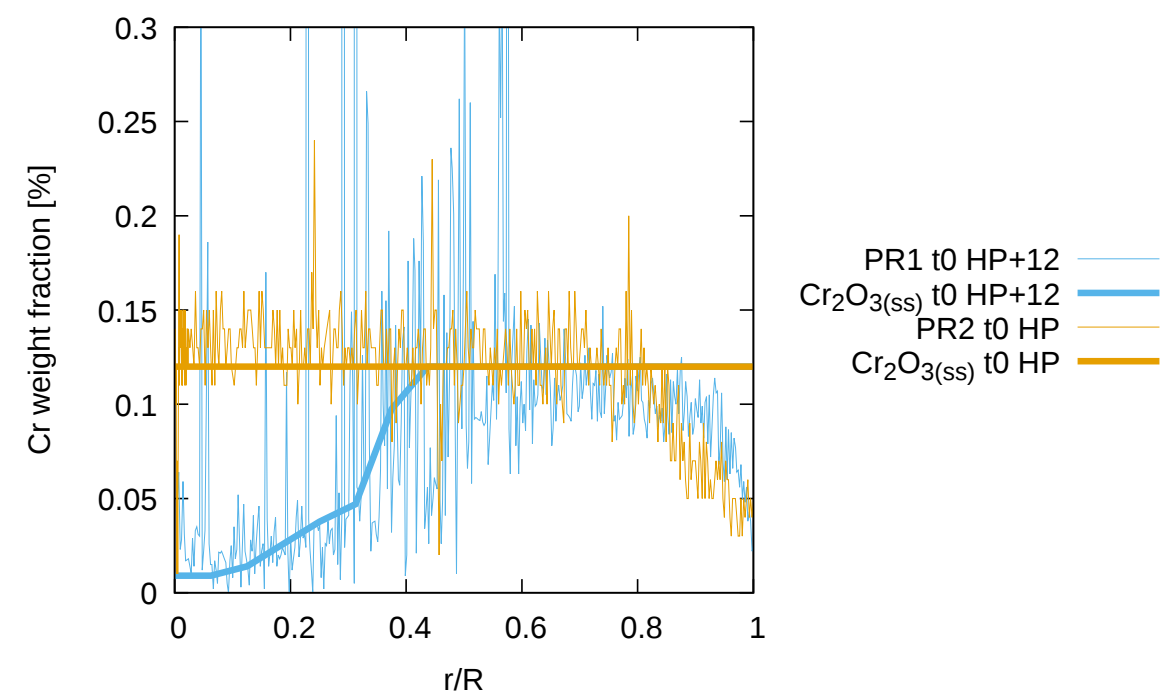

Figure 17: Calculated Cr weight fraction evolution during the Holding Period of power ramp compared to EPMA measurements after PR1 and PR2 tests.
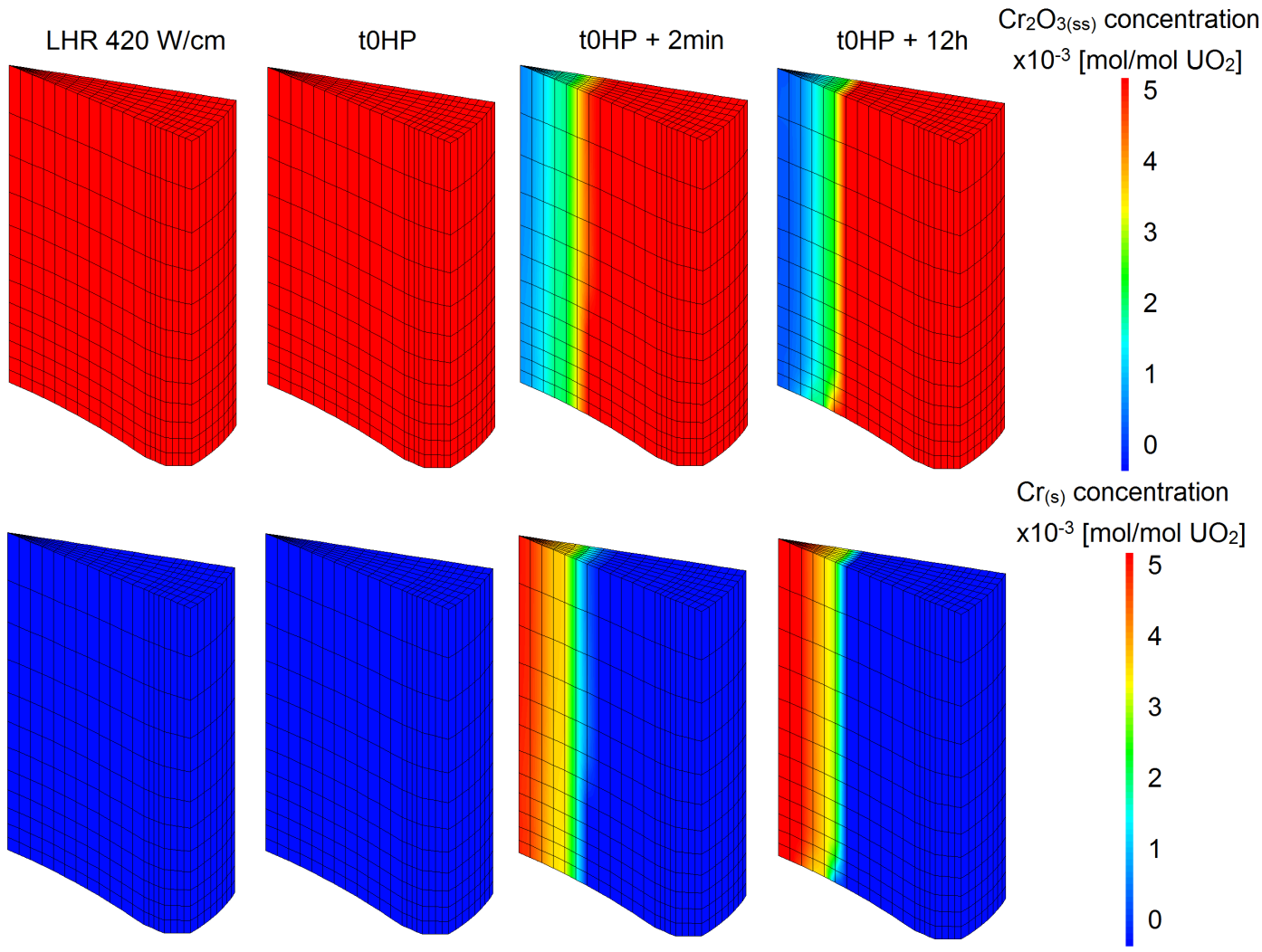

$\mathrm{x} 10^{-3}\left[\mathrm{~mol} / \mathrm{mol} \mathrm{UO}_{2}\right]$

Figure 18: Calculated $\mathrm{Cr}_{2} \mathrm{O}_{3(s s)}$ (upper plots) and $\mathrm{Cr}_{(s)}$ (lower plots) concentrations $\left[\mathrm{mol} / \mathrm{mol} \mathrm{\textrm {UO } _ { 2 }}\right]$ at different times during power ramp PR1. 

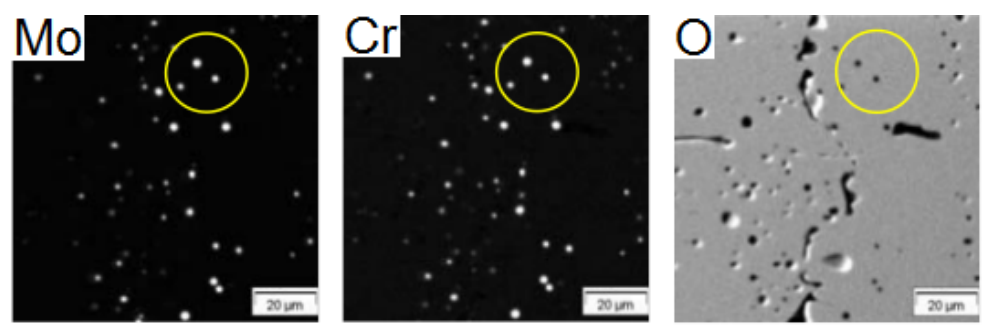

Figure 19: X-ray images of Mo, $\mathrm{Cr}$ and $\mathrm{O}$ at the pellet center [8] after power ramp PR1.
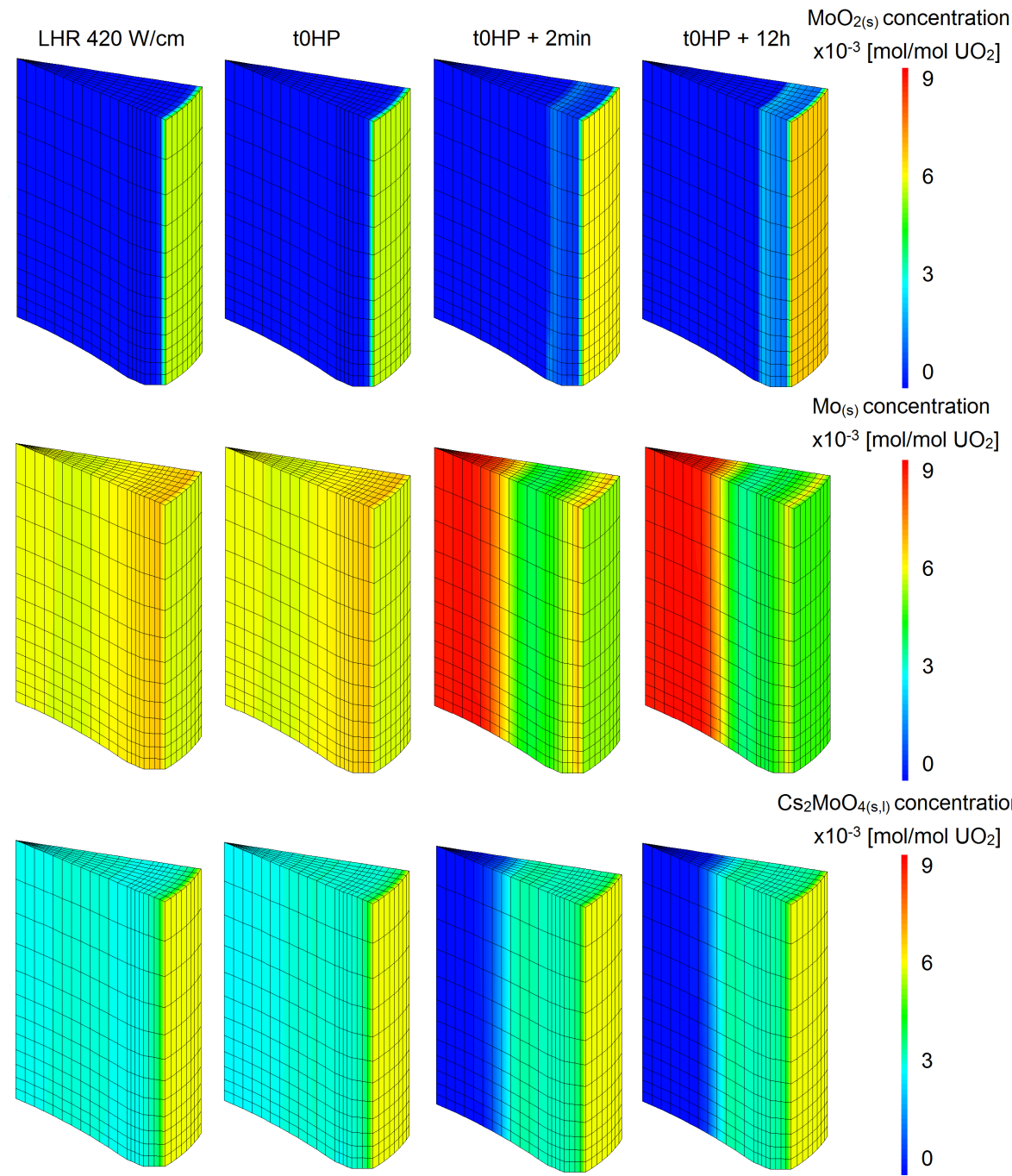

$\mathrm{Cs}_{2} \mathrm{MoO}_{4(\mathrm{~s}, \mathrm{l})}$ concentration

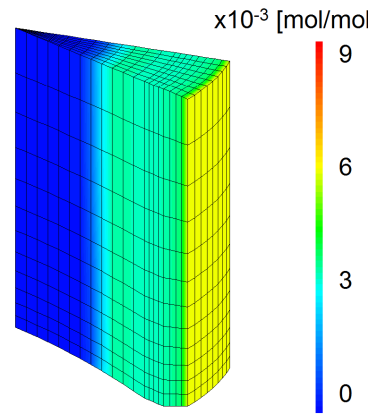

Figure 20: Calculated concentrations of $\mathrm{MoO}_{2(s)}$ (top figures), $\mathrm{Mo}_{(s)}$ (middle figures) and $\mathrm{Cs}_{2} \mathrm{MoO}_{4(s, l)}$ (bottom figures) at different times during power ramp PR1. 


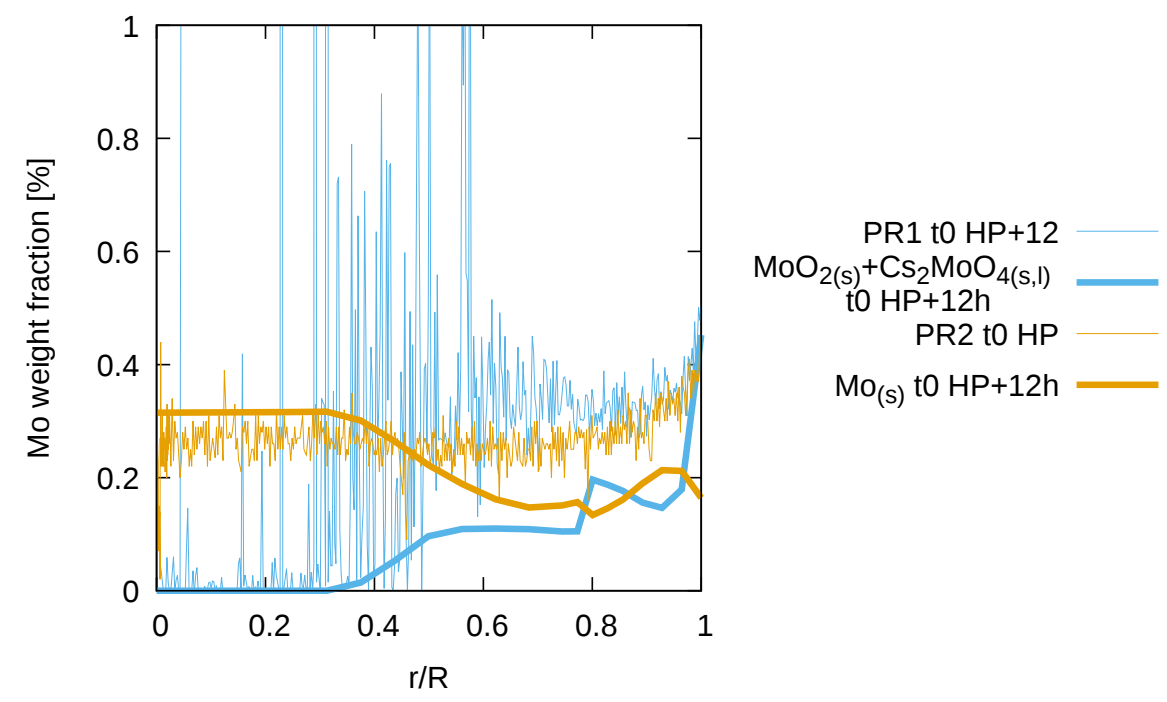

Figure 21: Calculated molybdenum oxides $\mathrm{MoO}_{x(s, l)}$ and metallic molybdenum $\mathrm{Mo}_{(s)}$ weight fraction evolution during the Holding Period of power ramp PR1 compared to EPMA measurements after power ramps PR1 and PR2. PR2 rodlet has a lower burnup than PR1 rodlet so the Mo weight fraction is lower on average.

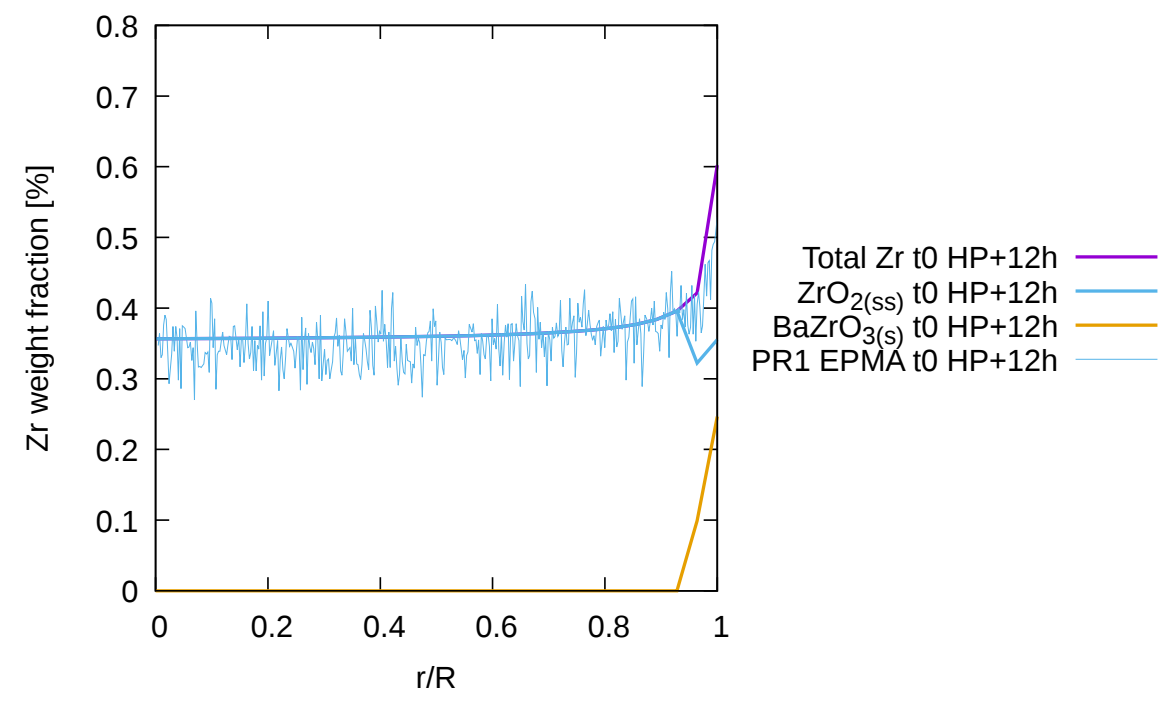

Figure 22: Calculated $\mathrm{ZrO}_{2(s s)}$ and $\mathrm{BaZrO}_{3(s)}$ concentrations compared to the EPMA measurement of $\mathrm{Zr}$ weight fraction after power ramp PR1. 

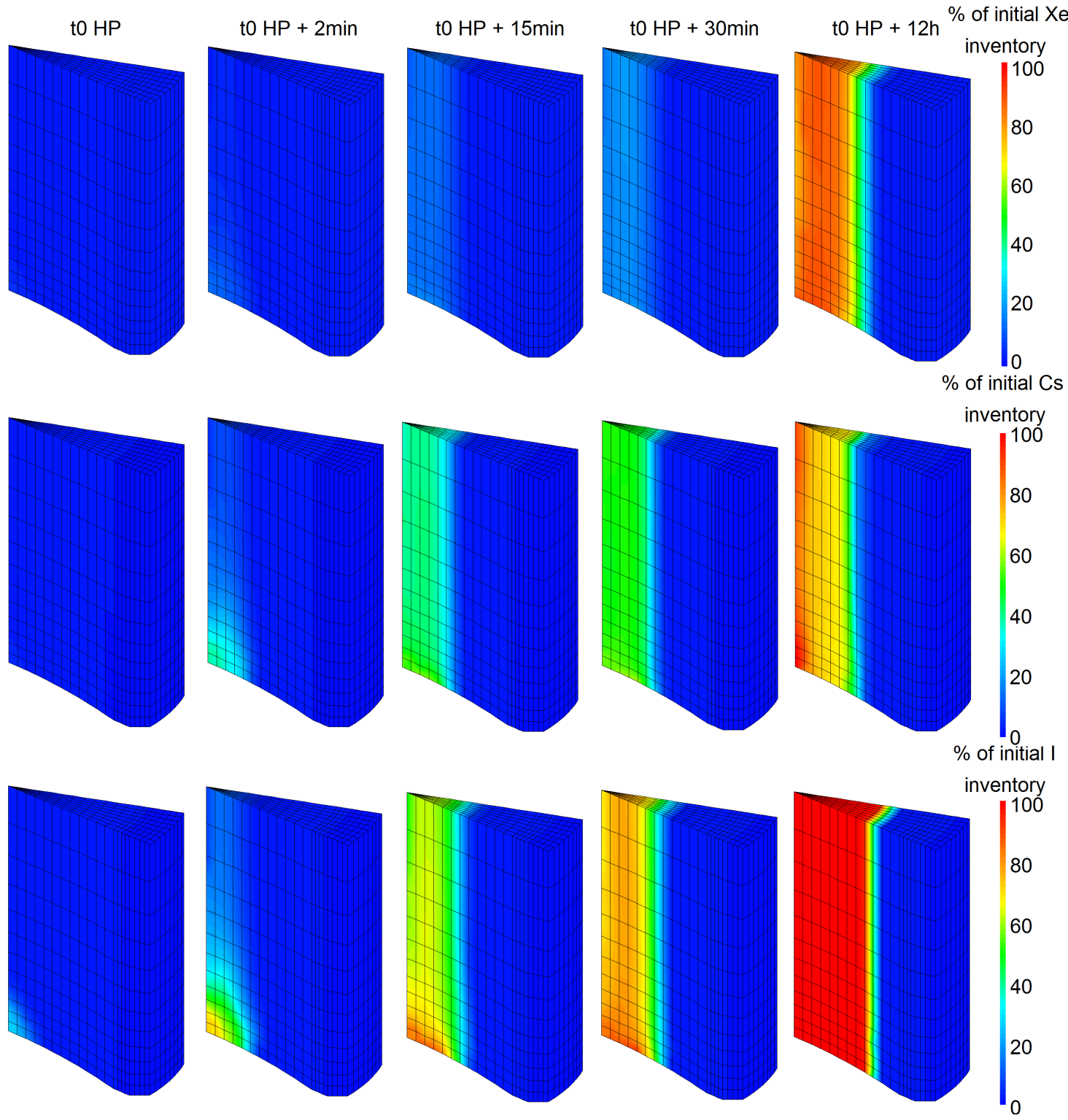

Figure 23: Calculated release of Xe (top), Cs (middle) and I (bottom) at different times during the power ramp PR1. Units - \% of initial inventory. 


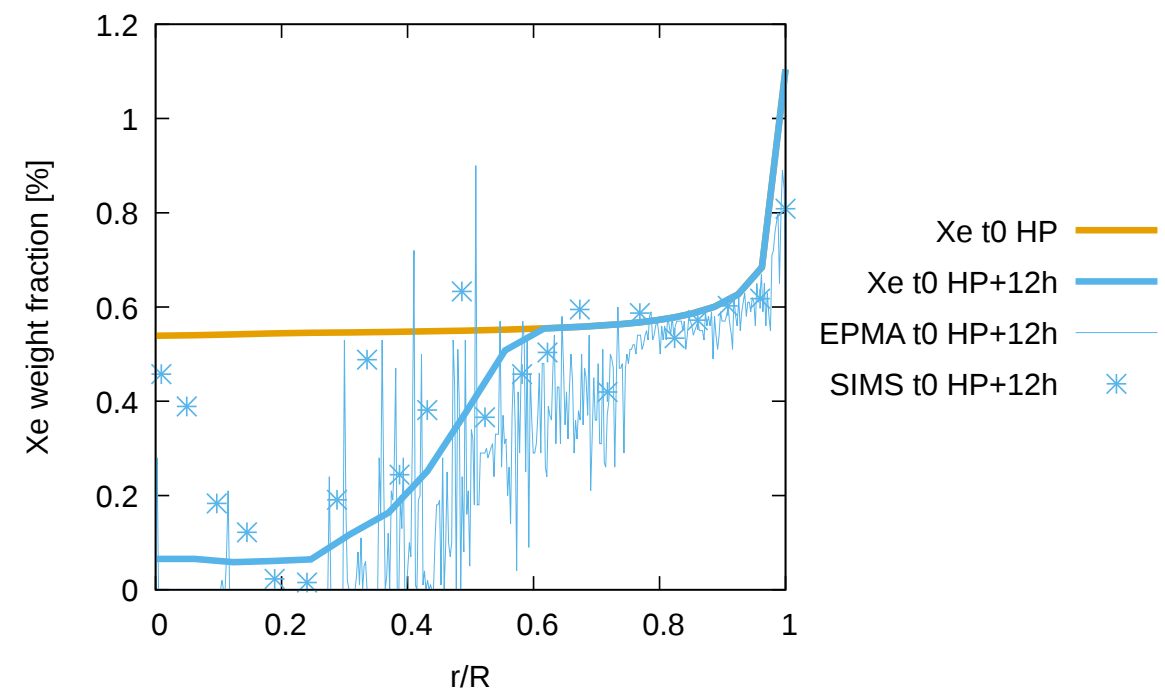

Figure 24: Calculated total (dissolved within grains, in intra- and inter-granular bubbles and in inter-granular pores) Xe weight fraction at the beginning and the end of the Holding Period of power ramp PR1 compared to EPMA and SIMS measurements. 

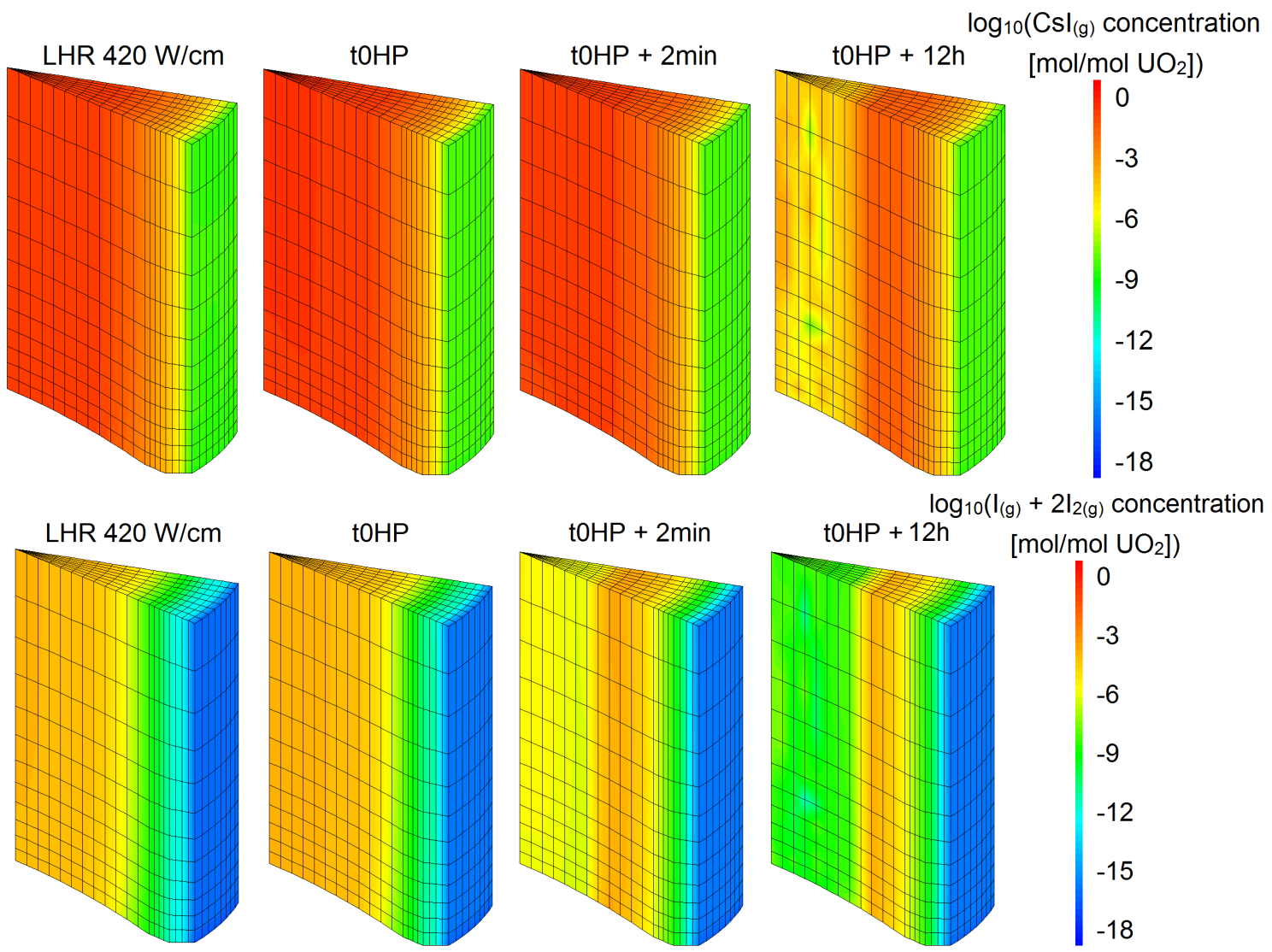

$\log _{10}\left(I_{(g)}+2 I_{2(g)}\right.$ concentration
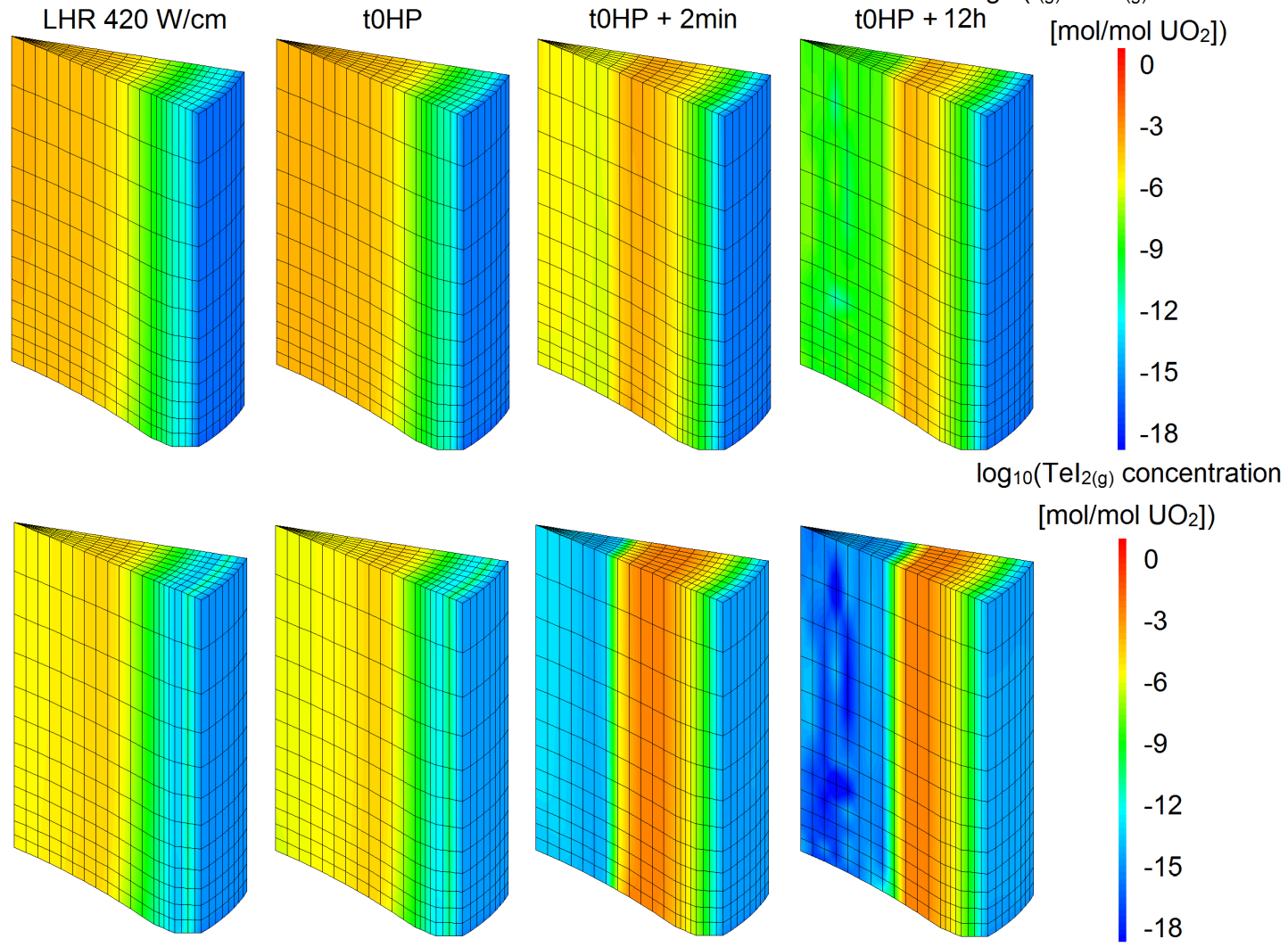

Figure 25: Calculated $\mathrm{CsI}_{(g)}, \mathrm{I}_{(g)}+2 \mathrm{I}_{2(g)}$ and $\mathrm{TeI}_{2(g)}$ concentrations in the fuel fragment at different times during power ramp PR1. 

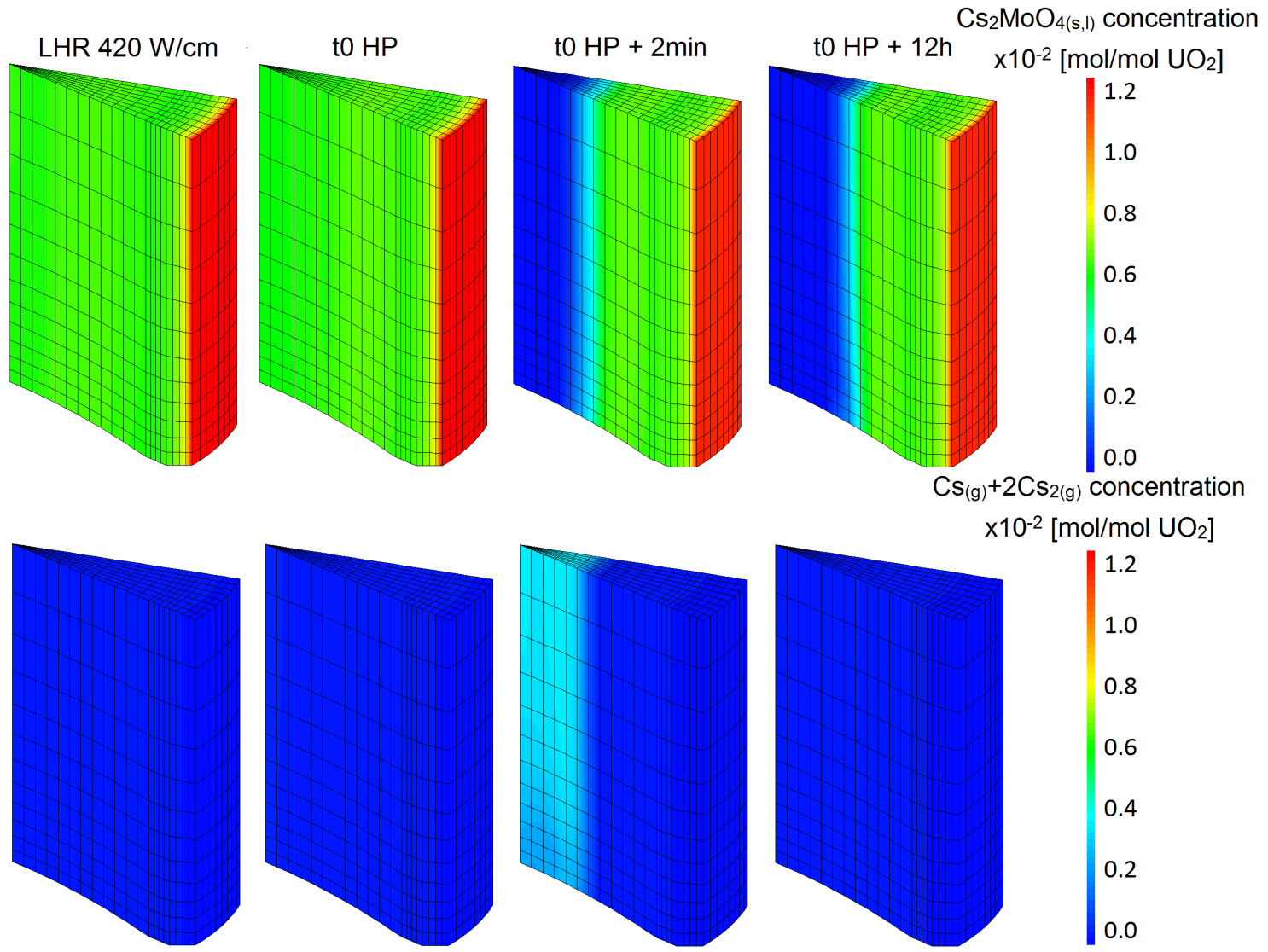

Figure 26: Calculated $\mathrm{Cs}_{2} \mathrm{MoO}_{4(s, l)}$ and $\mathrm{Cs}_{(g)}+2 \mathrm{Cs}_{2(g)}$ concentrations in the fuel fragment at different times during power ramp PR1. 


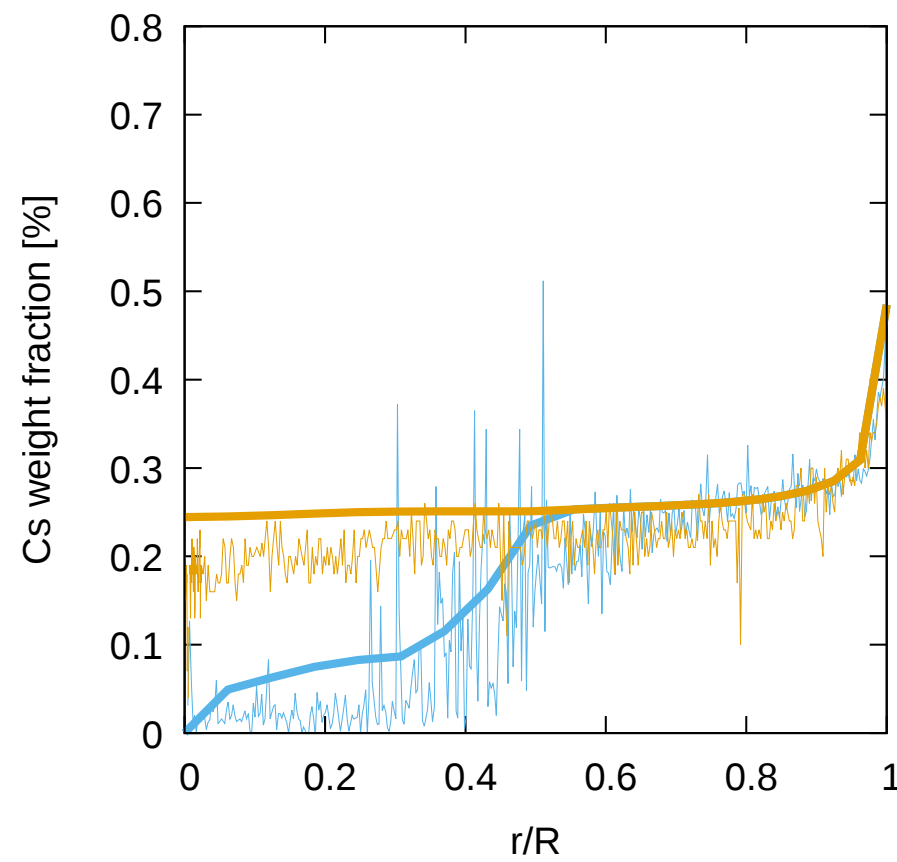

PR1 EPMA t0 HP+12h

Cs t0 HP+12h

PR2 EPMA t0 HP

Cs t0 HP

Figure 27: Calculated weight fractions of cesium at the beginning and at the end of the Holding Period of power ramp PR1 compared to EPMA measurements after power ramps PR1 and PR2.

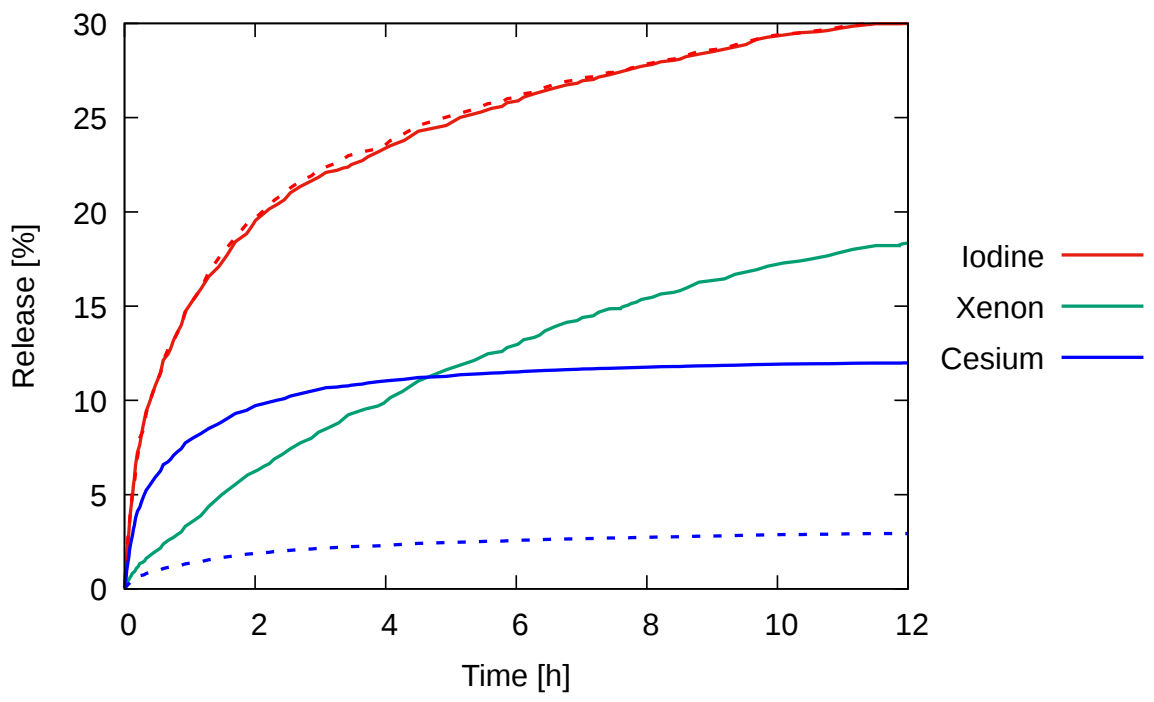

Figure 28: Calculated release of Cs, I and Xe during power ramp PR1. Solid lines refer to the simulation with oxygen thermodiffusion, dashed lines refer to the simulation without oxygen thermodiffusion ( $\mathrm{t}=0$ corresponds the beginning of the Holding Period, "t0"). 


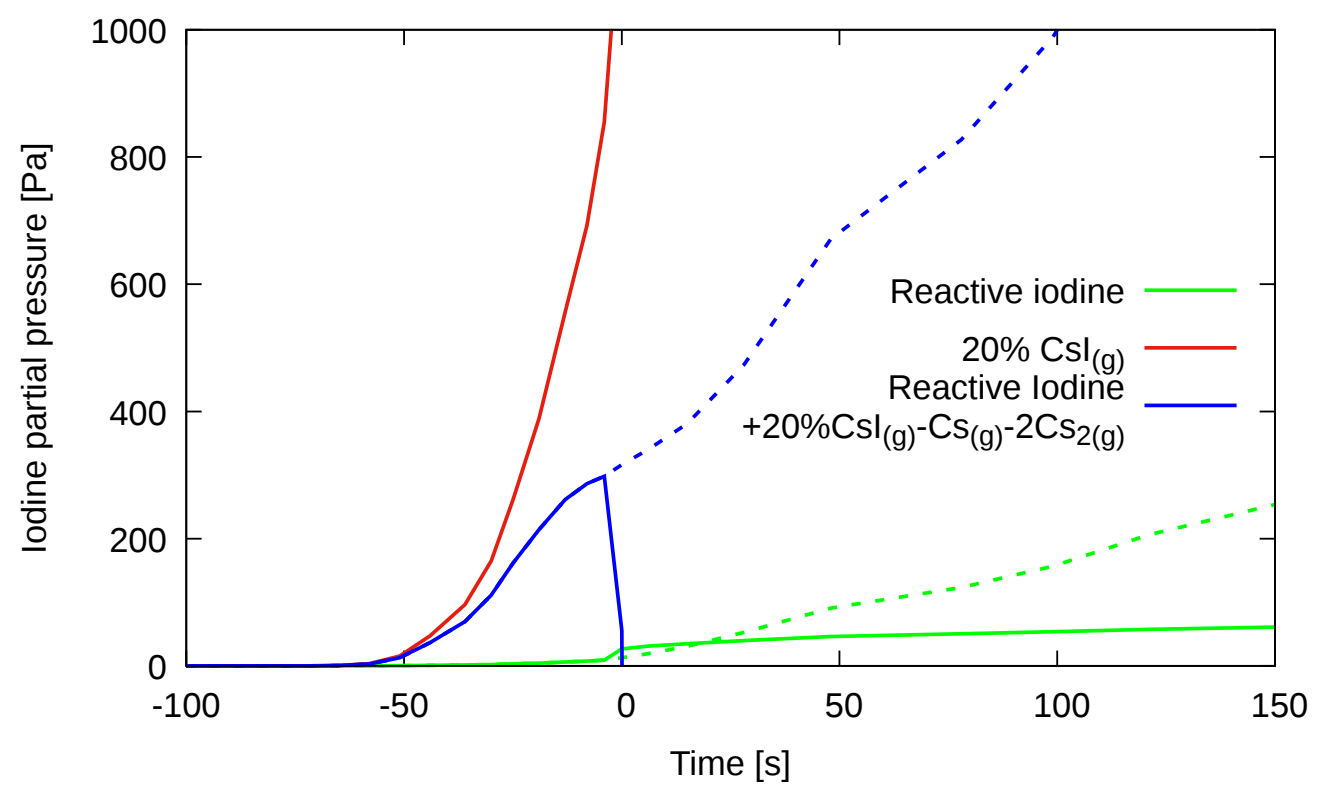

Figure 29: Calculated iodine partial pressure in function of time (0 at the $\mathrm{X}$ axis corresponds to "t0 HP"). Green curves refer to iodine from $\mathrm{I}_{2(g)}, \mathrm{I}_{(g)}$ and $\mathrm{TeI}_{2(g)}$, the red one to iodine pressure from $\mathrm{CsI}_{(g)}$ radiolysis and the blue curves show the sum of two first reduced by $\mathrm{Cs}_{(g)}$ and $\mathrm{Cs}_{2(g)}$. Solid lines - simulation with oxygen redistribution, dashed lines - simulation without oxygen redistribution. 


\section{Tables}

Table 1: Representative elements considered in ANGE calculations.

\begin{tabular}{ccc}
$\begin{array}{c}\text { Fission } \\
\text { Products }\end{array}$ & $\begin{array}{c}\text { Representative } \\
\text { element }\end{array}$ & Family \\
\hline $\mathrm{He}+\mathrm{Xe}+\mathrm{Kr}$ & $\mathrm{He}$ & Inert fission \\
$\mathrm{Cs}+\mathrm{Rb}$ & $\mathrm{Cs}$ & gas and \\
$\mathrm{I}+\mathrm{Br}$ & $\mathrm{I}$ & volatile fission \\
products \\
$\mathrm{Te}+\mathrm{Se}+\mathrm{Ge}+\mathrm{As}$ & $\mathrm{Te}$ & Stable oxides \\
\hline $\mathrm{Ba}+\mathrm{Sr}$ & $\mathrm{Ba}$ & \\
$\mathrm{Zr}+\mathrm{Nb}$ & $\mathrm{Zr}$ & Metallic fission \\
\hline $\mathrm{Mo}$ & $\mathrm{Mo}$ & products \\
\hline $\mathrm{Ru}+\mathrm{Tc}+\mathrm{Rh}$ & $\mathrm{Ru}$ & Fission \\
$\mathrm{Pd}+\mathrm{Sn}+\mathrm{Sb}$ & $\mathrm{Pd}$ & products and \\
$\mathrm{Ce}+\mathrm{Pr}$ & $\mathrm{Ce}$ & actinides in \\
$\mathrm{Eu}+\mathrm{Sm}$ & $\mathrm{Eu}$ & solid solution \\
$\mathrm{La}+\mathrm{Y}$ & $\mathrm{La}$ & in $\mathrm{UO}_{2}$ \\
$\mathrm{Gd}+\mathrm{Nd}+\mathrm{Pm}$ & $\mathrm{Gd}$ & $\mathrm{Pu}$ \\
$\mathrm{Pu}+\mathrm{Np}+\mathrm{Am}+\mathrm{Cm}$ & &
\end{tabular}

Table 2: Elemental compositions used in ANGE calculations.

\begin{tabular}{ccccc}
\hline $\begin{array}{c}\text { Representative } \\
\text { element }\end{array}$ & \multicolumn{4}{c}{ Concentration $\left(\mathbf{m o l} / \mathbf{m o l} \mathbf{U} \boldsymbol{O}_{\mathbf{2}}\right)$ at burnup of } \\
$\mathbf{2 0 W d} / \mathbf{t U}$ & $\mathbf{3 5} \mathbf{G W d} / \mathbf{t U}$ & $\mathbf{4 0} \mathbf{G W d} / \mathbf{t U}$ & $\mathbf{6 0} \mathbf{G W d} / \mathbf{t U}$ \\
\hline $\mathrm{He}$ & $6.56 \times 10^{-3}$ & $1.15 \times 10^{-2}$ & $1.31 \times 10^{-2}$ & $1.97 \times 10^{-2}$ \\
$\mathrm{Cs}$ & $3.75 \times 10^{-3}$ & $6.56 \times 10^{-3}$ & $7.50 \times 10^{-3}$ & $1.12 \times 10^{-2}$ \\
$\mathrm{I}$ & $2.80 \times 10^{-4}$ & $4.68 \times 10^{-4}$ & $5.35 \times 10^{-4}$ & $8.02 \times 10^{-4}$ \\
$\mathrm{Te}$ & $6.89 \times 10^{-4}$ & $1.20 \times 10^{-3}$ & $1.38 \times 10^{-3}$ & $2.06 \times 10^{-3}$ \\
$\mathrm{Ba}$ & $3.31 \times 10^{-3}$ & $5.80 \times 10^{-3}$ & $6.62 \times 10^{-3}$ & $9.93 \times 10^{-3}$ \\
$\mathrm{Zr}$ & $6.18 \times 10^{-3}$ & $1.08 \times 10^{-2}$ & $1.24 \times 10^{-2}$ & $1.85 \times 10^{-2}$ \\
$\mathrm{Mo}$ & $5.30 \times 10^{-3}$ & $9.27 \times 10^{-3}$ & $1.06 \times 10^{-2}$ & $1.60 \times 10^{-2}$ \\
$\mathrm{Ru}$ & $5.01 \times 10^{-3}$ & $8.76 \times 10^{-3}$ & $1.00 \times 10^{-2}$ & $1.50 \times 10^{-2}$ \\
$\mathrm{Pd}$ & $1.44 \times 10^{-3}$ & $2.52 \times 10^{-3}$ & $2.88 \times 10^{-3}$ & $4.32 \times 10^{-3}$ \\
$\mathrm{Ce}$ & $2.64 \times 10^{-3}$ & $4.61 \times 10^{-3}$ & $5.27 \times 10^{-3}$ & $7.91 \times 10^{-3}$ \\
$\mathrm{Eu}$ & $8.69 \times 10^{-4}$ & $1.52 \times 10^{-3}$ & $1.74 \times 10^{-3}$ & $2.61 \times 10^{-3}$ \\
$\mathrm{La}$ & $2.21 \times 10^{-3}$ & $3.87 \times 10^{-3}$ & $4.42 \times 10^{-3}$ & $6.63 \times 10^{-3}$ \\
$\mathrm{Gd}$ & $4.50 \times 10^{-3}$ & $7.88 \times 10^{-3}$ & $9.01 \times 10^{-3}$ & $1.35 \times 10^{-2}$ \\
$\mathrm{Pu}$ & $6.52 \times 10^{-3}$ & $1.14 \times 10^{-2}$ & $1.30 \times 10^{-2}$ & $1.96 \times 10^{-2}$ \\
$\mathrm{U}$ & $9.73 \times 10^{-1}$ & $9.53 \times 10^{-1}$ & $9.46 \times 10^{-1}$ & $9.18 \times 10^{-1}$ \\
$\mathrm{Cr}$ & $5.06 \times 10^{-3}$ & $5.06 \times 10^{-3}$ & $5.06 \times 10^{-3}$ & $5.06 \times 10^{-3}$ \\
\hline
\end{tabular}


Table 3: Main characteristics of the simulated power ramps PR1 and PR2.

\begin{tabular}{ccccccc}
\hline $\begin{array}{c}\text { Test } \\
\text { name }\end{array}$ & $\%{ }^{235} \mathbf{U}$ & $\begin{array}{c}\text { Dopant } \\
\mathbf{C r}_{2} \mathbf{O}_{3(s)} \\
(\mathbf{w t} \text { ) })\end{array}$ & $\begin{array}{c}\text { Initial } \\
\mathbf{O} / \mathbf{U}\end{array}$ & $\begin{array}{c}\text { Average } \\
\text { burnup } \\
(\mathbf{G W d} / \mathbf{t} \mathbf{U})\end{array}$ & $\begin{array}{c}\text { Max. } \\
\mathbf{L H R} \\
(\mathbf{W} / \mathbf{c m})\end{array}$ & $\begin{array}{c}\text { Holding } \\
\text { Period } \\
(\mathbf{h})\end{array}$ \\
\hline PR1 & 4.9 & 0.16 & $2.00 \pm 0.01$ & 38 & 470 & 12 \\
\hline PR2 & 4.9 & 0.16 & $2.00 \pm 0.01$ & 32 & 470 & 0 \\
\hline
\end{tabular}

